\title{
Size-segregated fluxes of mineral dust from a desert area of northern China by eddy covariance
}

\author{
G. Fratini $^{1}$, P. Ciccioli ${ }^{2}$, A. Febo ${ }^{3}$, A. Forgione ${ }^{4}$, and R. Valentini ${ }^{1}$ \\ ${ }^{1}$ Department of Forest Sciences and Resources (DiSAFRi), Università della Tuscia, 01100, Viterbo, Italy \\ ${ }^{2}$ Istituto di Metodologie Chimiche, Area della Ricerca del C.N.R. di Roma, 00016, Monterotondo Scalo, Italy \\ ${ }^{3}$ Istituto di Inquinamento Atmosferico, Area della Ricerca del C.N.R. di Roma, 00016, Monterotondo Scalo, Italy \\ ${ }^{4}$ FAI Instruments s.r.1., Fonte Nuova, Roma, Italy
}

Received: 24 January 2007 - Published in Atmos. Chem. Phys. Discuss.: 14 February 2007

Revised: 3 May 2007 - Accepted: 23 May 2007 - Published: 8 June 2007

\begin{abstract}
Mineral dust emission accounts for a substantial portion of particles present in the troposphere. It is emitted mostly from desert areas, mainly through intense storm episodes. The aim of this work was to quantify sizesegregated fluxes of mineral dust particles emitted during storm events occurring in desert areas of northern China (Alashan desert, Inner Mongolia), known to act as one of the strongest sources of mineral dust particles in the Asian continent. Long-range transport of mineral dust emitted in this area is responsible for the high particle concentrations reached in densely populated areas, including the city of Beijing. Based on a theoretical analysis, an eddy covariance system was built to get size-segregated fluxes of mineral dust particles with optical diameters ranging between 0.26 and $7.00 \mu \mathrm{m}$. The system was optimised to measure fluxes under intense storm event conditions. It was tested in two sites located in the Chinese portion of the Gobi desert. During the field campaign, an intense wind erosion event, classified as a "weak dust storm", was recorded in one of them. Data obtained during this event indicate that particle number fluxes were dominated by the finer fraction, whereas in terms of mass, coarser particle accounted for the largest portion. It was found that during the storm event, ratios of sizesegregated particle mass fluxes remained substantially constant and a simple parameterization of particle emission from total mass fluxes was possible. A strong correlation was also found between particle mass fluxes and the friction velocity. This relationship is extremely useful to investigate mechanisms of particle formation by wind erosion.
\end{abstract}

\footnotetext{
Correspondence to: G. Fratini

(gfratini@unitus.it)
}

\section{Introduction}

Mineral dust emission is one of the major natural sources of aerosols in the free troposphere (Heintzenberger et al., 2003). According to Penner et al. (2001), it accounts for ca. $37 \%$ of all aerosols present in air, with a mean global annual production of ca. $3000 \mathrm{Tg} \mathrm{yr}^{-1}$. The largest portion of this natural emission occurs in desert areas and is caused by wind erosion. Emission takes place most through acute episodes in which high wind velocities strongly promote creeping and saltation of sand-sized particles and the release of fine particles by suspension. Aerometric concentrations of mineral dust as high as $4.65 \mathrm{mg} / \mathrm{m}^{3}$ have been recorded in the low troposphere during intense desert storm events (Husar et al., 2001). Emitted particles, made of sand and pans of dry silty soil, are characterized by a size distribution falling most in the coarse mode (Heintzenberger et al., 2003). Under favourable conditions, particles smaller than $10 \mu \mathrm{m}$ undergo long range transport. Since they can travel for thousands of kilometres before they are deposited to the earth surface by dry and wet removal processes (Bates et al., 2006; Bonasoni et al., 2004; Chin et al., 2003), their impact is relevant at a global scale (Bates et al., 2006; Heintzenberger et al., 2003). Mineral dust aerosol particles can thus affect the Earth's climate by changing the radiation budget (Andreae, 1995; Bates et al., 2006; Cziczo et al., 2004; Tegen and Lacis, 1996) and by affecting the balance of atmospheric trace gases in the atmosphere (Bauer et al., 2004; Dentener et al., 1996; Zhang and Carmichael, 1999). In particular, mineral dust can reduce concentration of ozone and some photochemical oxidants in the atmosphere (Bonasoni et al., 2004; de Reus et al., 2005; Gusten et al., 1996; Seisel et al., 2005) and suppress precipitation (Rosenfeld et al., 2001).

Present estimates of mineral dust emission are affected, however, by large uncertainties because of the difficulty to

Published by Copernicus Publications on behalf of the European Geosciences Union. 
directly measure fluxes of aerosol particles during dust storm episodes (Bates et al., 2006; Chin et al., 2003). Several experimental approaches have been developed and used to evaluate mineral dust emission (Dong et al., 2003; Dong et al., 2004; Li et al., 2004; Ono et al., 2003). Most of them rely on indirect determinations requiring some theoretical assumptions about the way wind erosion leads to particle emission (Dong et al., 2003; Shao, 2000). However, with these approaches there is no way to verify if the actual emission truly follows modelled processes. So far, the only independent method used to derive fluxes of mineral dust emission from desert soils is the gradient method (Breshears et al., 2003; Houser and Nickling, 2001). Its correct application requires at least two sensors located at different heights. However, the assumption that the eddy diffusivity, derived for heat and water vapour fluxes from the friction velocity, also applies to particles cannot be easily verified; the derivation itself is critical, because it is usually based on the assumption of neutrally-stratified atmosphere (Stull, 1988). Recently, fast methods exploiting the eddy covariance (EC) approach have been developed and tested to derive time-integrated emission rates of aerosol particles released in urban areas from anthropogenic sources (Dorsey et al., 2002; Martensson et al., 2006; Nemitz et al., 2000). In particular, Nemitz et al. (2000) used an optical particle counter (OPC) to get size segregated fluxes of particles larger than $0.1 \mu \mathrm{m}$ in the city of Edinburgh. While OPC are suitable sensors for the fast detection of particles in the coarse mode (D3 mode), the possibility to apply the EC method to their flux determination needed to be verified because not all particles falling in this range might behave as passive scalars in an atmospheric flow field.

To select the particle range of mineral dust whose fluxes could have been measured by EC, a theoretical analysis was performed. It was concluded that this approach was possible for particles with an optical diameter ranging between 0.26 and $7.00 \mu \mathrm{m}$. An EC system for flux measurements of particles falling in this range was then built. It was specifically designed to measure fluxes during intense desert storm events. It was tested in two sites located in the Alashan plateau (Inner Mongolia, China), where storm events frequently occur in the spring season. This area is known to act as a major source of mineral dust in Asia (Chin et al., 2003; Qian et al., 2002; Wang et al., 2004; Xuan et al., 2004) and its longrange transport is responsible for the dramatic build up of particles in populated areas of northern China, including the city of Beijing. Size-segregated fluxes of particles measured in these two sites are reported and critically discussed. Cospectral analyses were performed to show the suitability of the EC system to provide reliable values of particle fluxes in the whole range investigated during the storm event. Results obtained can be relevant for modelling long-range transport of mineral dust particles in Asia and their impact on densely populated areas. They are also useful for a better parameterization of particle emission by wind erosion.

\section{Theoretical constraints to the application of the eddy covariance approach to mineral dust}

The eddy covariance approach has been developed and used to derive net vertical fluxes of gases and vapours from forest areas (Aubinet, 2000; Aubinet, 2003; Aubinet et al., 2001; Baldocchi et al., 1988; Valentini et al., 1996). It has been extended to particles under the assumption that they behave as gases. This assumption is substantially valid for ultra-fine aerosols emitted by some stationary sources (such as vehicular emission) or photochemically formed in the atmosphere. It might not be true for mineral dust particles. A theoretical treatment was thus needed to estimate the fraction of mineral dust to which the EC approach could have been safely applied. This can be done starting from the conservation equation of particle concentration in an atmospheric flow field:

$\frac{\partial c}{\partial t}+u_{p j} \frac{\partial c}{\partial x_{j}}=S+\gamma \nabla^{2} c$

where $c$ is the concentration of particles expressed in suitable units; $u_{p j}$, is the $j$ th component of the particle velocity vector $\boldsymbol{u}_{p} \equiv\left(u_{p}, v_{p}, w_{p}\right)$ in a suitable coordinate system, in which the $(x, y)$-plane is parallel to the local surface and positive $z$ points out of the surface; $\gamma$ is the particle diffusivity in atmosphere $\left(\mathrm{m}^{2} \mathrm{~s}^{-1}\right), S=S(\boldsymbol{x}, t)$ is the source/sink term. By applying the ensemble average operator to Eq. (1) and the Reynolds decomposition to all variables, Eq. (1) becomes:

$\frac{\partial \bar{c}}{\partial t}+\bar{u}_{p} \frac{\partial \bar{c}}{\partial x}+\overline{u_{p}^{\prime} \frac{\partial c^{\prime}}{\partial x}}+\bar{w}_{p} \frac{\partial \bar{c}}{\partial z}+\overline{w_{p}^{\prime} \frac{\partial c^{\prime}}{\partial z}}=\bar{S}+\gamma \nabla^{2} \bar{c}$

where the overbar refers to the ensemble average and primes to the fluctuations around the average. For the sake of simplicity, Eq. (2) was written for the case in which the $\mathrm{x}$-axis was aligned with the mean horizontal velocity.

The vector $\boldsymbol{u}_{\boldsymbol{p}}$, describing the particle velocity in a flow field, can be considered as the resultant of two components:

$\boldsymbol{u}_{\boldsymbol{p}}=\boldsymbol{u}+\boldsymbol{u}_{\boldsymbol{r}}$

where $\boldsymbol{u} \equiv(u, v, w)$ is the velocity of the fluid parcel in which the particle is immersed, and $\boldsymbol{u}_{r} \equiv\left(u_{r}, v_{r}, w_{r}\right)$ is the particleto-fluid relative velocity. In case of large particles, the last term of Eq. (3) cannot be neglected because they respond to gravity and have a finite response time to velocity changes, due to their inertia. In addition to these processes, a third one also contributes to $\boldsymbol{u}_{\boldsymbol{r}}$. It is the so-called trajectory crossing (tc) effect (Yudine, 1959). This accounts for the fact that the fluid surrounding the particles "changes" with time, because - due to inertia and gravity - particles tend to leave their companion eddy (Csanady, 1963; Shao, 2000).

Considering all these effects, $\boldsymbol{u}_{\boldsymbol{r}}$ can be written as:

$u_{r}=u_{r}^{g}+u_{r}^{i}+u_{r}^{t c}$

in which the components $g, i$ and $t c$ refer to the terms accounting for the gravity, inertia and trajectory-crossing effects, respectively. Equation (4) can be simplified by applying the Reynolds decomposition to $\boldsymbol{u}_{\boldsymbol{r}}$ and by analysing the 
contribution that each process gives to time averaged value of particle velocity $\left(\overline{\boldsymbol{u}}_{\boldsymbol{r}}\right)$ and to its fluctuating components $\left(\boldsymbol{u}_{\boldsymbol{r}}^{\prime}\right)$.

Since only gravity affects the average value of particle velocity, we can write:

$\overline{\boldsymbol{u}}_{\boldsymbol{r}}=\overline{\boldsymbol{u}}_{\boldsymbol{r}}^{\mathrm{g}}=w_{t} * \boldsymbol{k}$

where $w_{t}$ is the particle free fall velocity (also called terminal velocity) acting along the vertical axis ( $\boldsymbol{k}$ is the vertical unit vector). As far as fluctuations are concerned, the only components affecting $\boldsymbol{u}_{r}^{\prime}$ are those associated with inertia and trajectory-crossing effects $\left(\boldsymbol{u}_{\boldsymbol{r}}^{\prime}=\boldsymbol{u}_{\boldsymbol{r}}^{\prime}+\boldsymbol{u}_{\boldsymbol{r}}^{\prime t c}\right)$. It has been shown (Csanady, 1963), however, that in the atmosphere the contribution of inertia is negligible for particles with diameters up to about $500 \mu \mathrm{m}$. The fluctuating component of $\boldsymbol{u}_{\boldsymbol{r}}$ can thus be simplified as:

$u_{r}^{\prime}=u_{r}^{\prime} t c$

Taking into account Eqs. (5) and (6), Eq. (2) becomes:

$\frac{\partial \bar{c}}{\partial t}+\bar{u} \frac{\partial \bar{c}}{\partial x}+\overline{u_{p}^{\prime} \frac{\partial c^{\prime}}{\partial x}}+\left(\bar{w}+w_{t}\right) \frac{\partial \bar{c}}{\partial z}+\overline{w_{p}^{\prime} \frac{\partial c^{\prime}}{\partial z}}=\bar{S}+\gamma \nabla^{2} \bar{c}$

If molecular diffusion is small compared to the turbulent stresses and no horizontal turbulent flux divergence occurs, integration of Eq. (7) along the vertical axes $\mathrm{z}$ gives rise to:

$$
\begin{aligned}
& \int_{o}^{h_{m}} S d z=\left.\overline{w_{p}^{\prime} c^{\prime}}\right|_{z=h_{m}}+\int_{o}^{h_{m}} w_{t} \frac{\partial \bar{c}}{\partial z} d z+\int_{0}^{h_{m}} \frac{\partial \bar{c}}{\partial t} d z+\int_{0}^{h_{m}} \bar{u} \frac{\partial \bar{c}}{\partial x} d z+\int_{0}^{h_{m}} \bar{w} \frac{\partial \bar{c}}{\partial z} d z \\
& \begin{array}{lllllll}
I & I I & I I I & I V & V & V I
\end{array}
\end{aligned}
$$

where $I$ is the scalar source/sink term; $I I$ represents the vertical turbulent flux at height $h_{m}$; III is the flux due to gravitational advection, $I V$ represents the storage of the scalar below the measurement height; $V$ is the flux due to horizontal advection and $V I$ the one due to fluid vertical advection.

If atmospheric stationarity and horizontal homogeneity are achieved, the last three terms of the right-hand side of Eq. (8) can be neglected, and the working equation for the $\mathrm{EC}$ of particles becomes:

$F_{p}=\int_{o}^{h_{m}} S d z=\left.\overline{w_{p}^{\prime} c^{\prime}}\right|_{z=h_{m}}+\left.w_{t} \bar{c}\right|_{z=h_{m}}$

in which $h_{m}$ is the height at which measurements are performed. Equation (9) states that the particle source/sink term, equivalent to the net release of particles $F_{p}$, equals the sum of the vertical eddy flux and the gravitational settling flux.

This expression reduces to the one commonly used for gases:

$F_{p}=\overline{w^{\prime} c^{\prime}}$

when:

$w_{t} \cong 0 \quad$ and $\quad w_{r}^{\prime t c} \cong 0 \Rightarrow w_{p}^{\prime} \cong w^{\prime}$
Conditions in Eq. (11) occur when gravitational settling is small with respect to the turbulent flux, and the trajectory crossing effect is negligible.

To assess in which conditions gravitational settling can be neglected, a preliminary analysis was performed on the basis of the particle terminal velocity $w_{t}$. According to Shao (2000) particles are likely to remain airborne if the mean vertical Lagrangian velocity of the air parcel surrounding them is larger than their $w_{t}$. The following equation can be used to calculate $w_{t}$, for small particles subject only to gravity and aerodynamic drag:

$w_{t}=-\frac{\sigma_{p} g d^{2}}{18 v}$

where $\sigma_{p}$ is the particle-to-air density ratio, $g$ is the gravity $\left(\mathrm{ms}^{-2}\right)$ and $v$ is the kinematic viscosity of the air $\left(\mathrm{m}^{2} \mathrm{~s}^{-1}\right)$. Since a particle-to-air density ratio of ca. 2200 can be reasonably assumed for mineral dust, particles with optical diameters of 7.00 and $1.00 \mu \mathrm{m}$ should have settling velocities of ca. $3.9 \times 10^{-3} \mathrm{~ms}^{-1}$ and $7.9 \times 10^{-5} \mathrm{~ms}^{-1}$, respectively. In a neutrally-stratified atmospheric surface layer, the mean vertical component of the Lagrangian velocity can be estimated (Hunt and Weber, 1979) by the product $\kappa u_{*}$, between the Von Kármán constant $(\kappa \cong 0.4)$ and the friction velocity, $u_{*}$. By considering that during wind erosion events $u_{*}$ is always well above $0.2 \mathrm{~ms}^{-1}$, the corresponding mean Lagrangian velocity is higher than $8 \times 10^{-2} \mathrm{~ms}^{-1}$. This implies that gravitational settling can be neglected with respect to turbulent diffusion.

These calculations suggested that Eq. (10) could have been safely applied to derive the total vertical fluxes of particles with an optical diameter as high as $7 \mu \mathrm{m}$ under normal conditions, as long as the $t c$ effect can be neglected.

The aerodynamic diameter $\left(D_{\mathrm{ae}}\right)$ corresponding to this optical fraction $\left(D_{\text {opt }}\right)$ can be estimated by recalling that:

$D_{\mathrm{ae}}=D_{\mathrm{opt}} \times \rho_{p}^{1 / 2} \cdot f\left(D_{\mathrm{opt}}, m\right)$

in which $\rho_{p}$ is the normalized particle density and $m$ is the particle refractive index. The function $f=f\left(D_{\mathrm{opt}}, m\right)$, is usually taken in the form of a 2 nd-order polynomial function in $m$, the coefficients depending on the diameter range (McMeeking, 2004). For northern Asian dust, the refractive index can be assumed to be $m=1.53$ (Clarke et al., $2004)$, and $f\left(D_{\text {opt }}, m\right)$ is around 0.85 . Since the density of fine soil particles measured in the sites investigated was $\rho_{p}=2.5 \mathrm{~g} \mathrm{~cm}^{-3}$ (see below), $D_{\mathrm{ae}} \cong 1.35 \times D_{\text {opt }}$. This means that fluxes of particles with an aerodynamic range up to ca. $9.5 \mu \mathrm{m}$ could have been safely measured by EC.

The equivalence between net fluxes and the co-variance between the vertical wind and particle concentrations requires also that stringent criteria are followed in the selection of the measuring site to meet horizontal homogeneity and isotropy conditions. In the flat, desert areas of northern China where only sparse, short vegetation and small dunes 


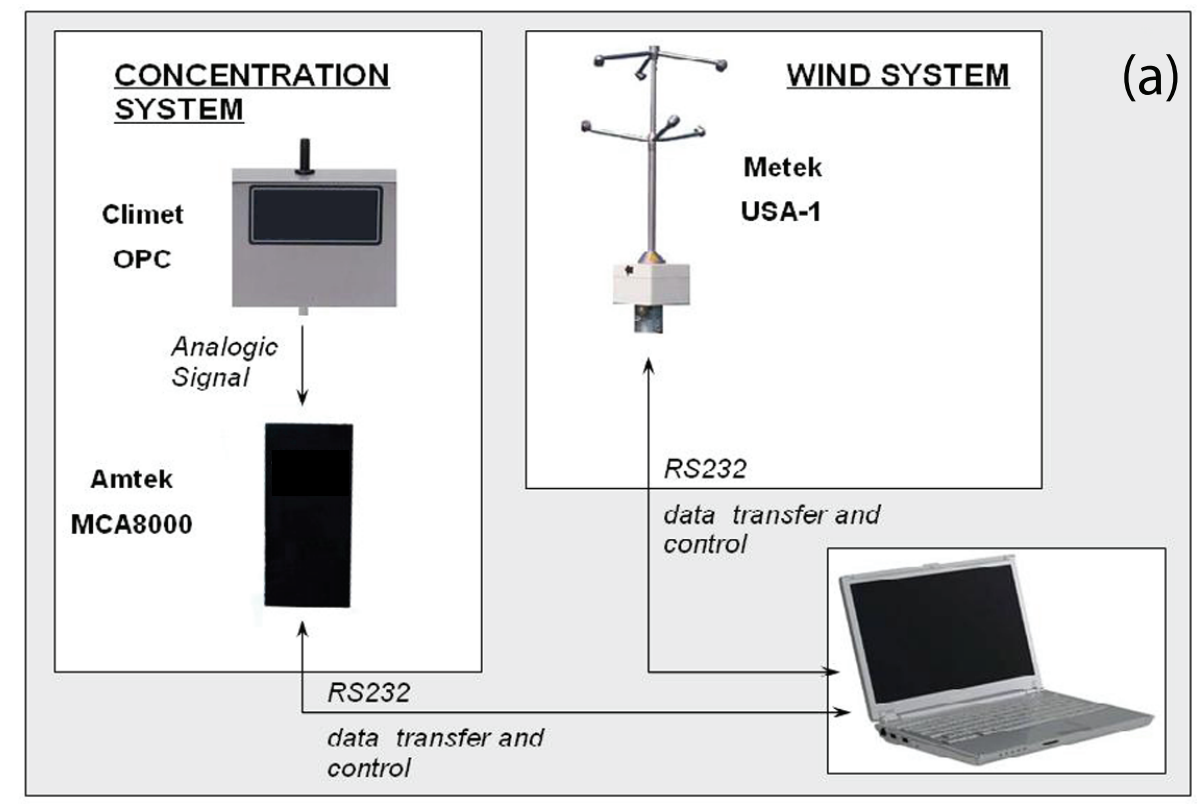

Fig. 1a. Simplified view of the eddy covariance system for measuring fluxes of mineral dust particles (EOLO).

are present (see next section), these conditions are fully met. For the same reasons, footprint assessment is not critical. On the basis of traditional EC practice, it can be estimated by the product $100 \times h_{m}$ (Sozzi et al., 2002). The storage term is also negligible because of the highly turbulent conditions in which emission occurs and substantial lack of any surface where particles could be deposited.

\section{Materials and methods}

3.1 The eddy covariance system for mineral dust particles

Once the upper limit of the measurable aerodynamic range has been defined, the actual range was selected on the basis of the sensing device used. With the selected OPC, counting efficiencies larger than $90 \%$ were possible for particles with an optical diameter ranging between 0.26 and $7.00 \mu \mathrm{m}$. By using the conversion procedures described in the previous section, size-segregated fluxes of mineral dust particles with aerodynamic diameters between 0.35 and $9.50 \mu \mathrm{m}$ could have been measured with our system. It covers the largest portion of mineral dust mass subject to long range transport. A schematic view of the EC system built is shown in Fig. 1a. From now on, we will refer to it by using the acronym EOLO, which stands for Eddy cOvariance-based upLift Observation system. It was jointly developed with FAI Instruments s.r.l., (Fonte Nuova, Roma, Italy).

The system is comprised of two main components: the wind system and the concentration system. The wind system consisted of an ultrasonic anemometer Metek USA-1, (Metek GmbH, Elmshorn, Germany), allowing fast and ac- curate measurements of the 3-D wind velocity and sonic temperature; this last parameter also provides a good estimation of the air temperature, especially in the dry conditions occurring in desert areas. The concentration system, shown in Fig. 1b, includes several parts. The most important are the OPC (CI-3100 series, Climet Instruments Co., Redlands, CA, USA) and the Multi-Channel Analyzers (MCA8000, Amptek Inc., Bedford, MA, USA). To minimize uncertainties, the inlet of the measuring system was directly attached to the anemometer. In our design, sampled particles were split in two channels: the so-called finer channel $\left(D_{\text {opt }}\right.$ from 0.26 to $0.54 \mu \mathrm{m}$ ) and the coarser channel ( $D_{\text {opt }}$ from 0.54 to $7.00 \mu \mathrm{m}$ ). The system simultaneously acquires data from the two channels through dedicated MCA devices. "Finer" and "coarser" particle number concentrations are stored every $30 \mathrm{~min}$. This time period, which also corresponds to the averaging time in Eq. (9), was selected on the basis of the experience acquired in the framework of EC applied to gases. It represents the best compromise to achieve a correct sampling of turbulent eddies and to get averaging times short enough to meet the steady-state conditions required by the theory (Aubinet, 2000; Aubinet et al., 2001; Goulden et al., 1996).

The acquisition frequency was also carefully chosen. While high sampling frequencies are needed for an accurate collection of smaller eddies, their use might lead to statistically poor sampling of large particles. In the case of mineral dust, it was found that an acquisition frequency of $5 \mathrm{~Hz}$ represented the best compromise between these opposite requirements. In any case, the system was built in a way that all acquisition features, with the exception of the "finer" and 


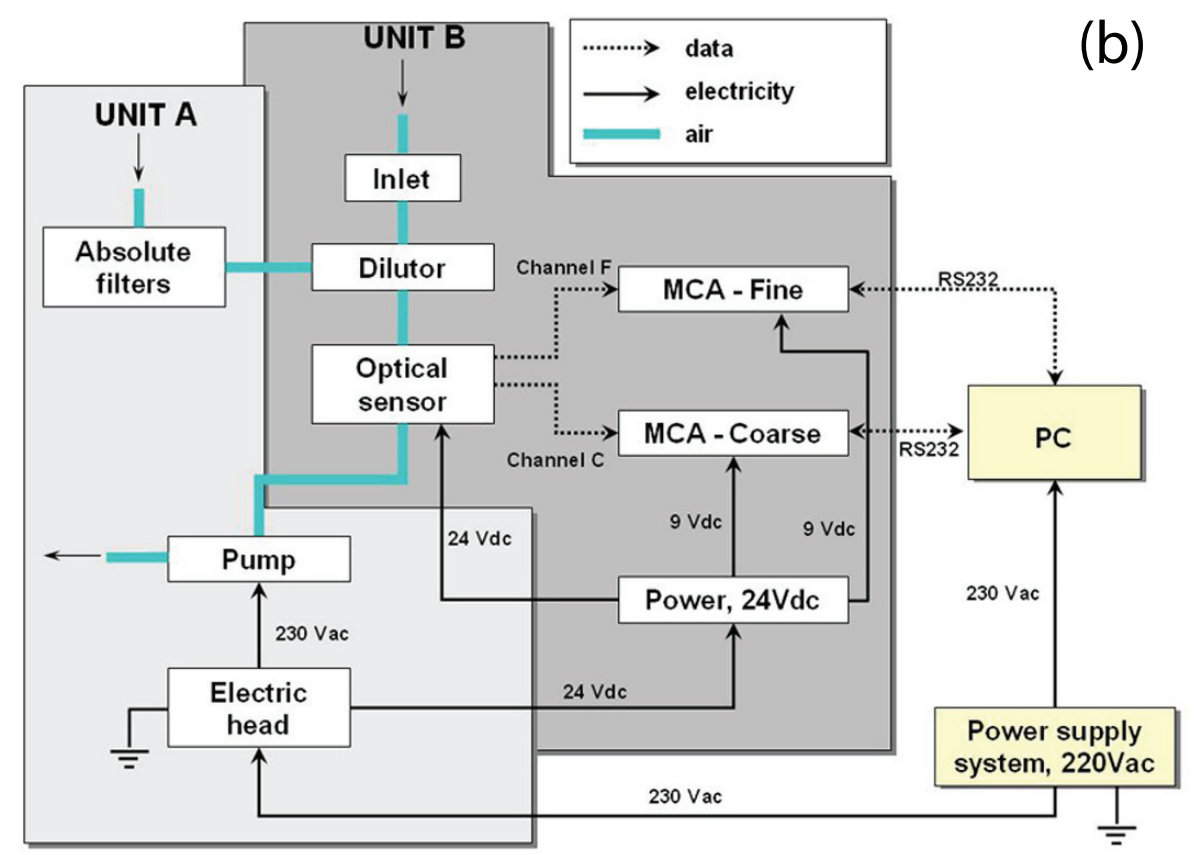

Fig. 1b. Schematic view of the concentration system of EOLO, engineered by FAI Instruments, s.r.l. (Fonte Nuova, Roma, Italy).

"coarser" channel selection, could have been changed by the operator.

A pump was used to deliver the sampled air to the sensing device, where each particle was counted and sized. Details of the pneumatic circuit and of the data acquisition system are shown in Fig. 1b. The flow rate of the aspirating pump was $28.41 \mathrm{~min}^{-1}$, but only $5 \%\left(1.421 \mathrm{~min}^{-1}\right)$ was actually used to sample particles, the remaining flow was used for dilution with clean air. Dilution was needed to avoid saturation of the particle counter during storm events, in which very high concentrations of particles could have been reached. The dilution step was performed at $3 \mathrm{~cm}$ distance from the sampling inlet to limit dumping effects occurring in laminar flow regimes. The diluted sample was then delivered to the sensor through a line made up of a Teflon tube $120 \mathrm{~cm}$ long and with an inner diameter of $6.35 \mathrm{~mm}$. The flow regime in the tube was turbulent, with a Re of ca. 6280. The constancy of the flow rate was achieved by inserting a critical nozzle along the flow path. In this way, dumping effects in particle counting arising from the occurrence of a laminar flow regime in the sampling and detection line were minimized (Buzorius et al., 2003). An almost real-time response was achieved in the OPC because the light scattering of particles was measured on a thin section of a $5.3 \mathrm{~mm}$ tube in which turbulent flow was maintained. Since the system uses a laser beam as a light source, the cross section of the counting area is extremely small, and the time response of the instrument essentially determined by the time needed to acquire and convert signals.
The system was able to simultaneously record counts of particles falling in 18 size ranges. The number of particles per unit of sampled volume (number concentration) was than obtained. It will be indicated in the text as $N_{a, b}$, where $a$ and $b$ define the range under consideration. $N$ will be replaced by $M$ when referring to mass concentrations. This latter value were estimated by assuming that particles were spherical and exhibited the same, constant density.

An ANSI C program was developed to control the hardware devices, to synchronize the acquisition of the two channels and to acquire and store the raw data. Before calculating fluxes, data were pre-processed in order to account for the time-lag between the acquisition of wind and concentration data. The time-lag was estimated through a covariance analysis. Data were de-trended to eliminate possible long-term trends (Gash and Culf, 1996) and an axis rotation was performed to align the $\mathrm{x}$-axis to the mean wind direction and nullify the covariance between $v$ and $w$ (Wilczak et al., 2001). Concentrations and fluxes of mineral dust particles were calculated for each of the 18 ranges selected with a 30 min time step. Several turbulence parameters such as the Monin-Obukhov length, the friction velocity and the sensible heat flux, were also calculated. The system was located inside a tough case to protect the instrumentation from shocks or falls occurring during transport or during storm events.

\subsection{Investigated sites}

Although a total of six sites, all located in northern China, were investigated, we report here only data collected in two 


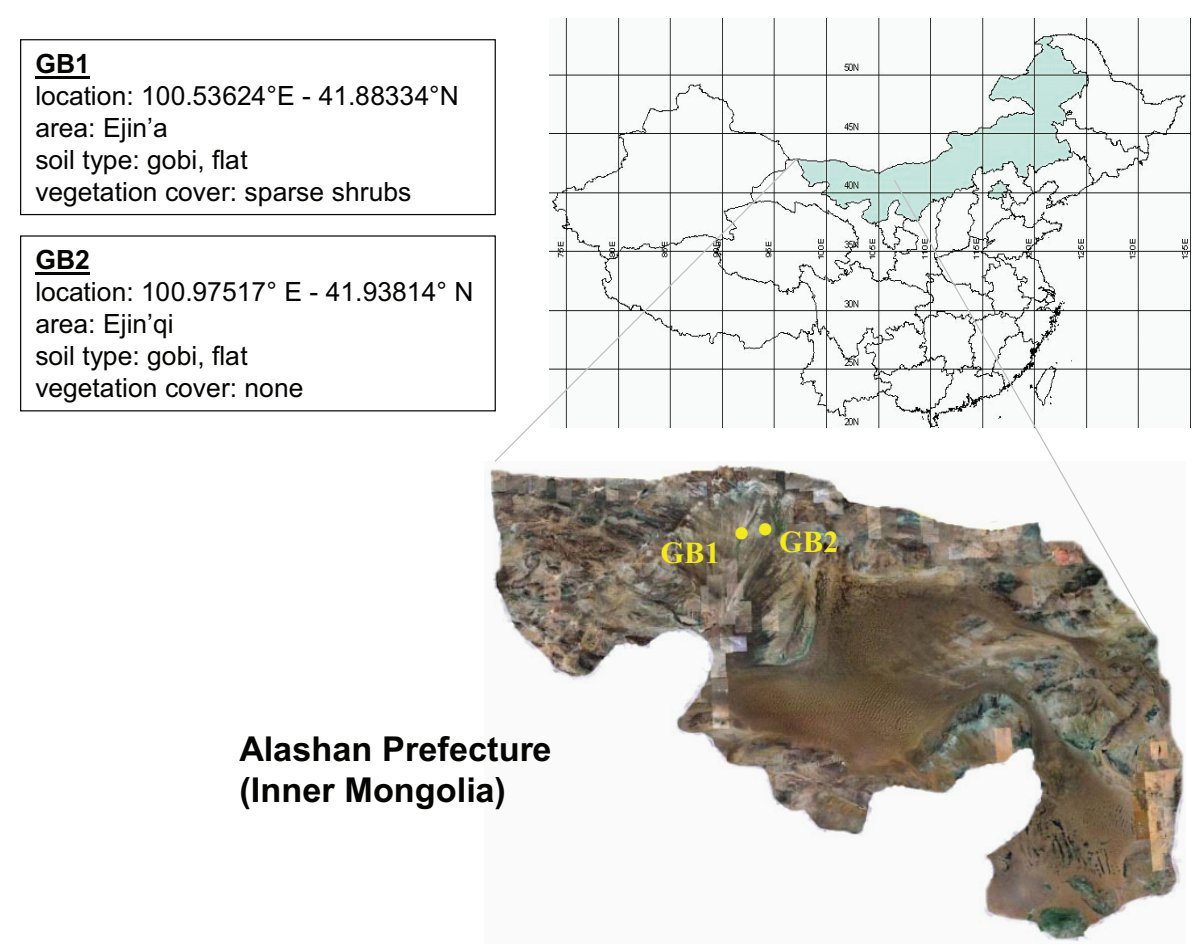

Fig. 2. Location of sites (GB1 and GB2) where mineral dust fluxes were measured by EOLO. These are located in the Ejina area of the Alashan Prefecture (Inner Mongolia, China).

sites of the Gobi desert. Both of them (identified in the paper as GB1 and GB2) are located in the Ejin'a area of the Alashan Prefecture. Their exact location is shown in Fig. 2. In all cases land-cover features were those typical of the area. The GB1 site, which is flat and highly homogeneous, is characterized by bare soil where only sparse shrubs are present. The short vegetation is partly covered by small, sandy dunes extending downwind. They originated from deposition of sand and dust transported during previous storm events. The GB2 site is also flat and highly homogeneous, but is comprised only by bare soil free from any vegetation cover. We restrict the discussion to these sites because they provided a better test of the ability of our system to provide sizesegregated fluxes of mineral dust particles by EC, because of the frequent occurrence of desert storm events. This, combined with limited interferences arising from human activities allowed to better highlight some features associated with the wind erosion process. Particle density was determined by means of picnometer-based standard procedures (ISO/TS, 2004).

\section{Results and discussion}

4.1 Cumulated and size-segregated particle concentrations

Figure 3 reports the time series of total particle number concentrations $\left(N_{0.26-7.00}\right)$ that were recorded by EOLO at the
GB1 site. As it can be seen from the figure, only one high concentration event was recorded during the monitoring campaign and it occurred in the last days of May. Particle number concentrations recorded during this event were one to two orders of magnitude higher than those recorded in previous days.

Since no particle mass monitors were available at the site, a comparison was made with data from the Navy Aerosol Analysis and Prediction System (NAAPS) (http: //www.nrlmry.navy.mil/aerosol/). The model, developed by Westphal et al. (1988) predicts 6-hour averaged data of mineral dust mass concentration smaller than $5.00 \mu \mathrm{m}$ (aerodynamic diameter) at the surface layer. Model outputs have a sufficient spatial resolution to follow mineral dust evolution in the investigated area. Particle mass concentrations lower than $5.00 \mu \mathrm{m}$ were obtained from EOLO by summing particle number contributions from all channels with an optical diameter smaller than ca. $4.00 \mu \mathrm{m}$ and by converting these values into mass $\left(M_{0.26-4.00}\right.$ in $\left.\mu \mathrm{g} \mathrm{m}^{-3}\right)$.

Figure 4 compares the time evolution of particle mass concentration predicted by the NAAPS model (a) with those measured by EOLO (b). Data refer to a storm recorded at the GB1 in the last two days of the campaign. It was classified as a "weak storm event" by the meteorological service of Ejin'a, based on the visibility, wind intensity and duration of the windy period. Although the time resolution of the model did not allow us to verify short-term variations, 


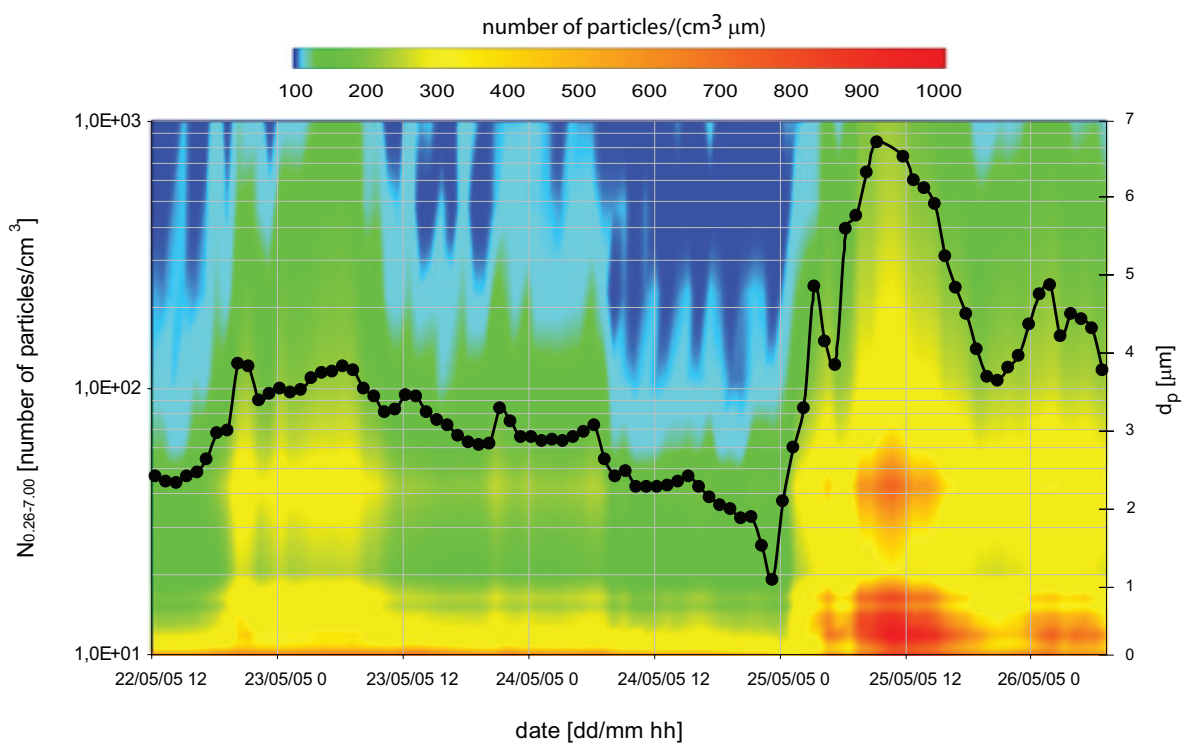

Fig. 3. Time evolution of total particle number concentration sensed by EOLO $\left(N_{0.26-7.00}\right.$, bold line with circles), recorded from 22 to 26 May 2005 at the GB1 site, Ejina area. Concentrations are represented on a logarithmic scale. On the background, contour plot of size-segregated particle number concentration are reported.
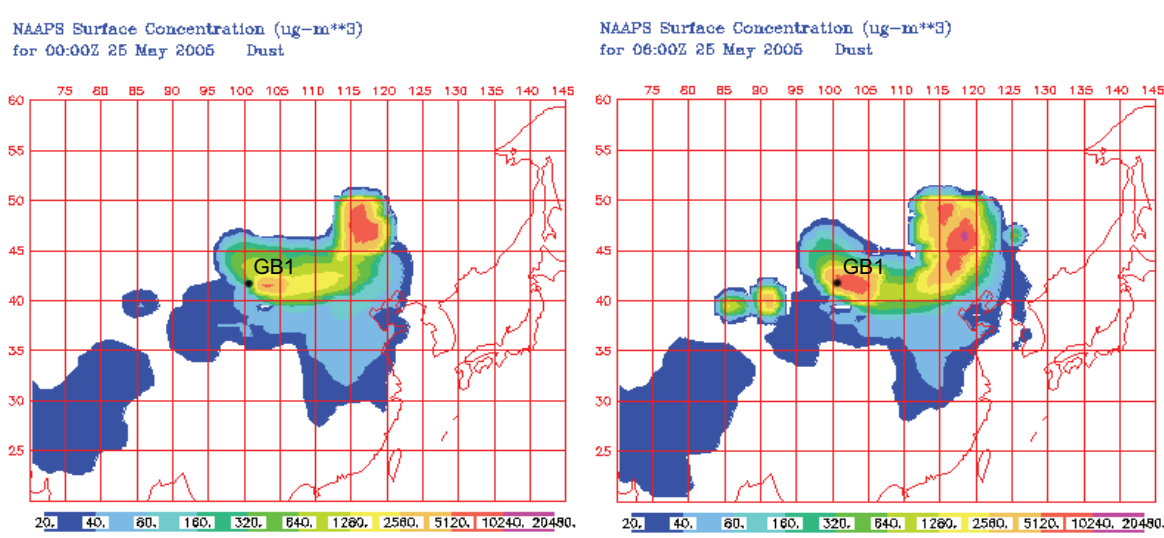
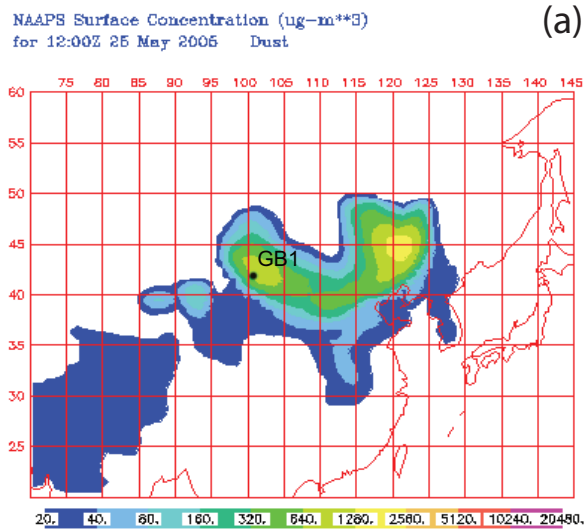

Fig. 4a. Mineral dust mass concentration during the strong dust event of 25 May 2005 at GB1 site: NAAPS "Dust" plots at surface layer; each plot represents 6-hours average concentration values. GB1 site location is also showed.

a good consistency was observed between the two datasets. This suggested that the bulk of mineral dust particles emitted in the area was falling within the size-range sensed by EOLO. It is worth noting that the good agreement between measured and modelled values was not limited to this episode but was observed in almost all sites in which the impact of anthropogenic sources was limited, regardless of the occurrence of storms events.

Data obtained at the GB1 site during the event were also used to evaluate the evolution of mineral dust particles under high emission conditions. $N$ and $M$ values of particles recorded in the 18 size ranges investigated were separated into classes as a function of the friction velocity. Three classes, corresponding to average values of $0.15,0.30$ and $0.45 \mathrm{~ms}^{-1}$, were selected for this analysis. In Fig. 5a data of particle number concentrations are reported, whereas mass concentrations are shown in Fig. 5b. Solid lines with symbols were used to identify averaged values of profiles belonging to each friction velocity class. Dotted lines refer, instead, to individual measurements. Although a general increase of $N$ with the friction velocity was observed, the one occurring in the $0.40-0.60 \mu \mathrm{m}$ range was suggestive of a substantial generation of finer particles above a certain value of the friction velocity. The release of these particles does not directly come from the wind action. Such particles are, indeed, so strongly attached to large sandy grains, to form a sort of permanent coating hard to be removed even at high wind speeds. Their release can be better explained by the sandblasting process induced by saltating particles (Shao, 2000). 
(b)
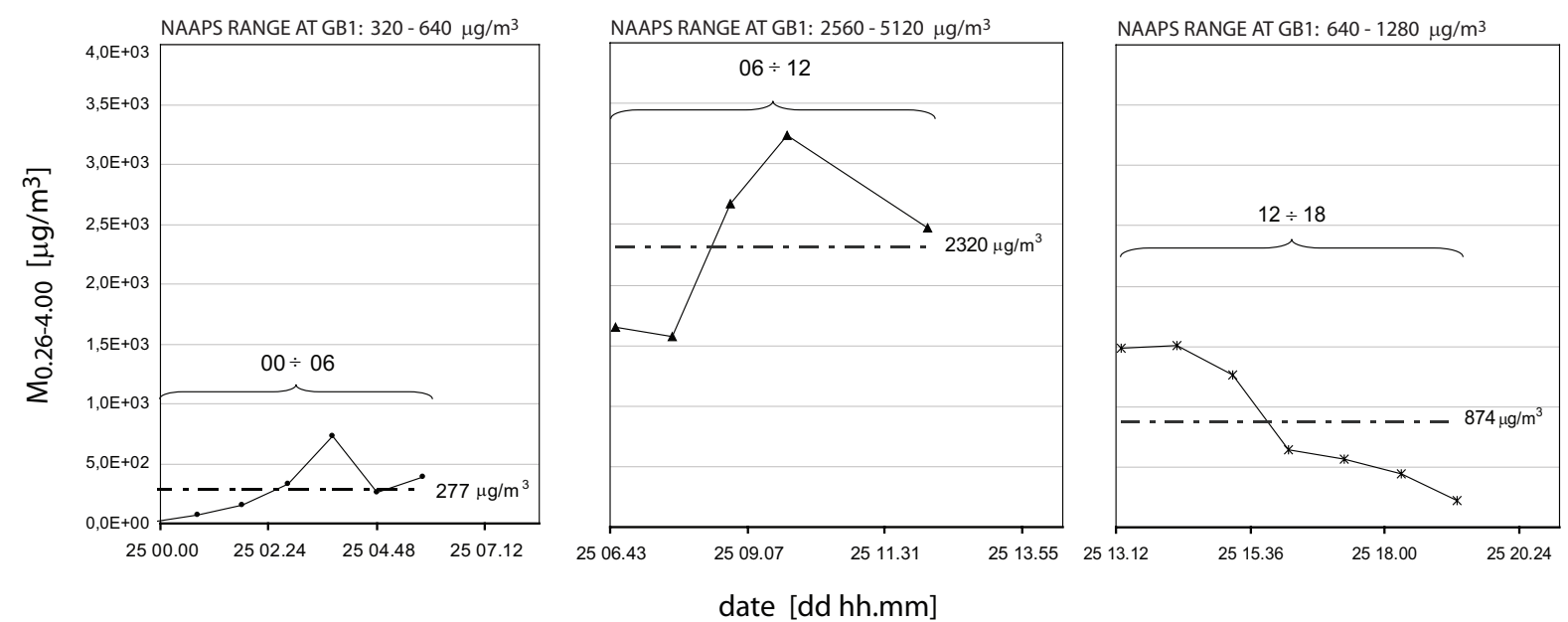

Fig. 4b. Mineral dust mass concentration during the strong dust event of 25 May 2005 at GB1 site: mass concentration time series derived by EOLO. Units are $\mu \mathrm{g} / \mathrm{m}^{3}$. Over each plot, the corresponding range predicted by NAAPS at the GB1 location is reported, derived from Fig. 4a.
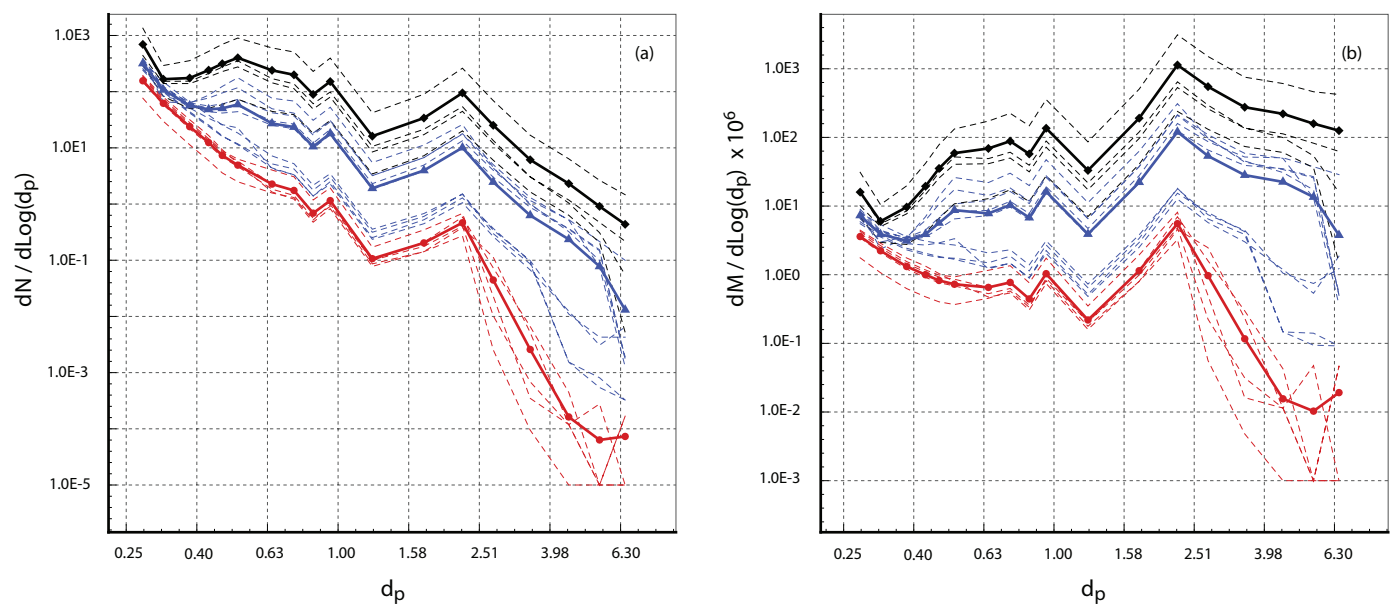

Fig. 5. Number (a) and mass (b) concentrations vs. particle diameters during dust event at the GB1 site. Units are [number of particles/cm ${ }^{3}$ ] and $\left[\mu \mathrm{g} / \mathrm{cm}^{3}\right]$ for the number and mass concentrations, respectively; diameters are expressed in $\mu \mathrm{m}$. Red, blue and black thick lines with symbols are the average profiles of the $0.15,0.30$ and $0.45 \mathrm{~ms}^{-1}$ wind friction classes, respectively. The highest wind friction class refers to the most intense period. Light, dashed lines are examples of profiles in the three classes.

As shown in Fig. 5b, trends of particle mass concentrations as a function of the friction velocity are quite different from those followed by particle number concentrations. Mass concentrations of coarser particles increase much more rapidly than particle number during the dust event. While in low turbulent conditions the contribution of finer particles $\left(M_{0.26-0.90}\right)$ to the total mass is comparable to that of coarser particles $\left(M_{2.00-4.00}\right)$, a larger increase in the coarser mode occurs during the dust event. It is such that the total mass concentrations can be considered to be almost exclusively formed by particles falling in the $M_{2.00-7.00}$ range.
4.2 Co-spectral analysis and uncertainties in flux measurements

A co-spectral analysis was performed on the raw data in order to find out if $t c$ effect was affecting the motion of particles falling in any size range. To focus attention on the vertical dynamics, co-spectra are calculated by using the vertical wind speed, $w$, as the transporting variable.

Based on the classical theory of turbulence K41 (Kolmogorov, 1941), it can be assumed that trajectory crossing effects are negligible and data statistically valid whenever particle concentrations behave as passive scalars in the inertial frequency sub-range. 
(a)
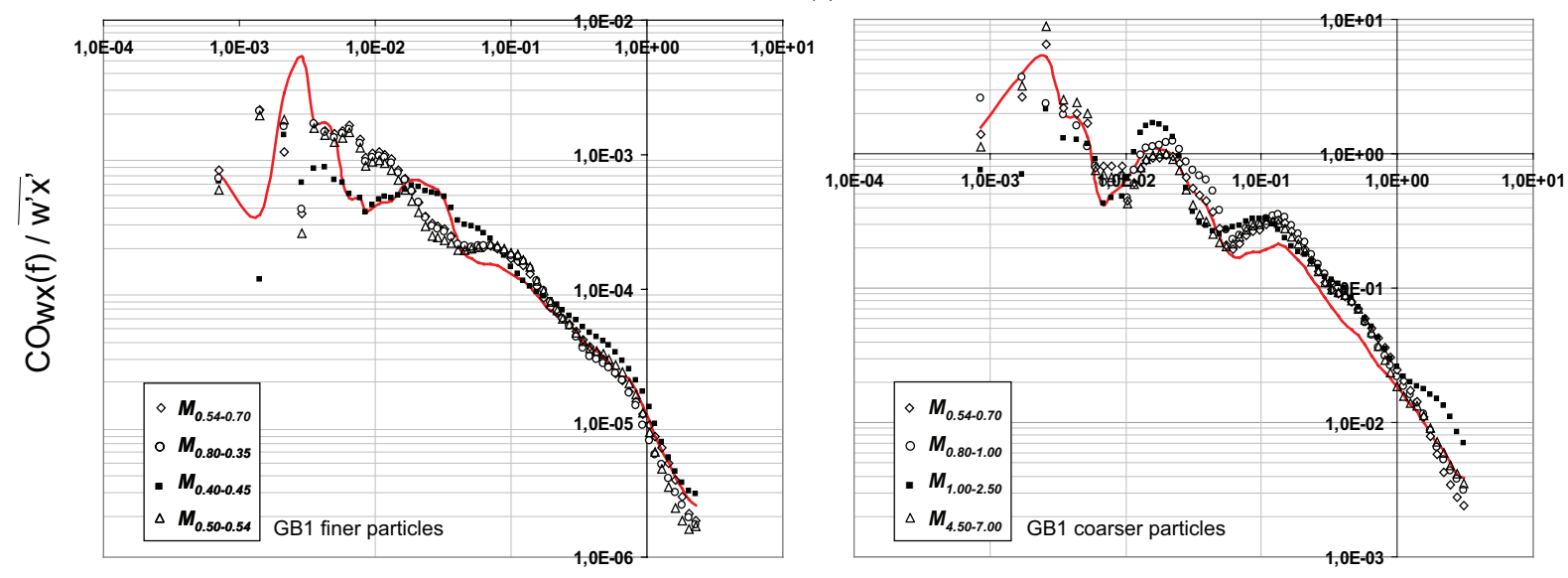

(b)

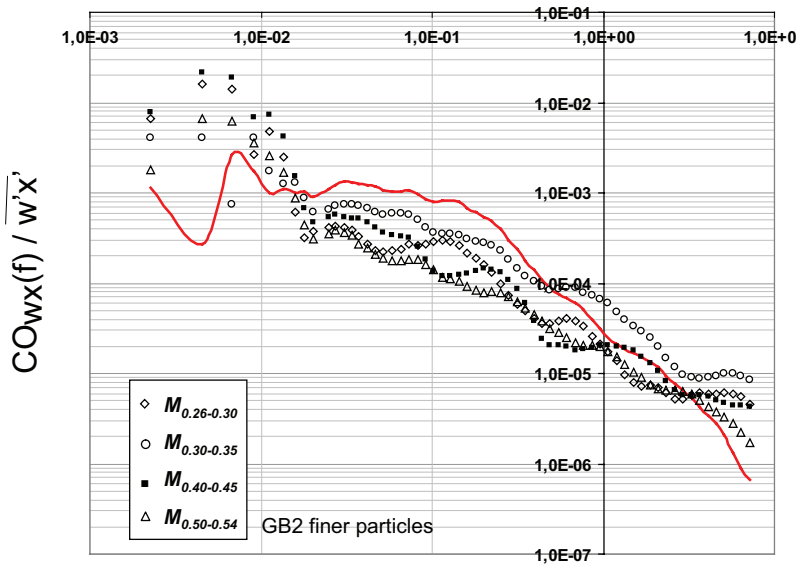

$f_{n}$

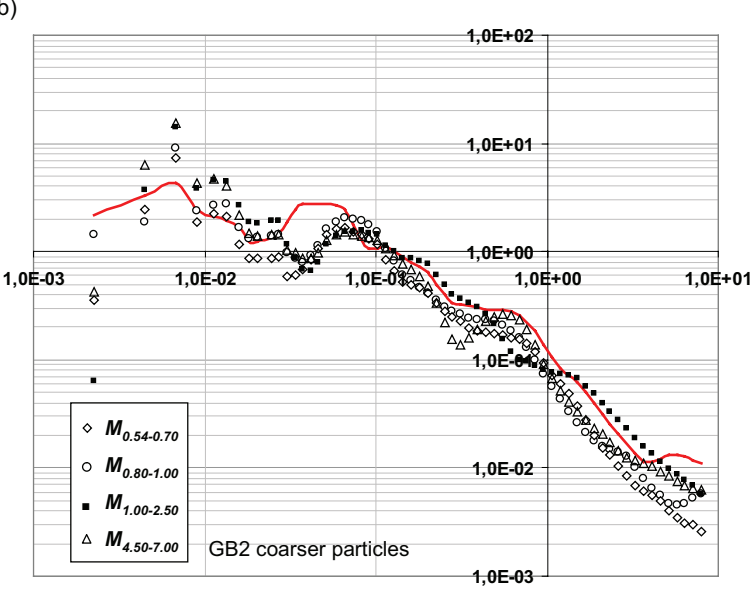

$f_{n}$

Fig. 6. Normalized co-spectra of vertical wind and sonic temperature (red curves) and of vertical wind and particle concentration (symbols), as a function of the normalized frequency ( $U$ is used here to indicate the mean horizontal component of the wind speed). The term "finer particles" indicates all particles ranging between 0.26 and $0.54 \mu \mathrm{m}$ (optical diameter), whereas the term "coarser particles" is used for the size range between 0.54 and $7.00 \mu \mathrm{m}$. Plots refer to co-spectra of 30-min datasets for (a) a strong dust event at GB1 site and (b) a weak dust event at GB2 sites. The co-spectra of wind and sonic temperature is used as a reference.

Different approaches can be used to find out if particle behave as an ideal scalar. The most used consists in comparing co-spectra of particles determined in the inertial subrange with those theoretically expected (Martensson et al., 2006). Since theoretical calculations are possible only for specific turbulence conditions, such as neutrally stratified atmospheres (Stull, 1988), this approach is not the most appropriate when, such as in our case, rapid changes in turbulence take place. In these conditions, a comparison between the normalized co-spectra of particles with those of an experimental variable known to be passively transported by the air flow represents a better option to analyze the concentration dynamics. If particles behave as a perfect scalar, their co-spectra should match those of the experimental variable in the inertial sub-range. In our case, co-spectral analysis was performed by comparing normalized co-spectra of particle concentration with those of the sonic temperature, which can be certainly assimilated to a passive scalar. Results obtained are summarized in Figs. 6a and b, where data of regularized and normalized co-spectra of particle concentrations and sonic temperatures are plotted as a function of the normalized frequency $f_{n}$. This latter parameter is defined by $f_{n}=f * h_{m} / U$, where $f$ is the frequency in $\mathrm{Hz}, h_{m}$ is the measurement height, $\left(h_{m}=12 \mathrm{~m}\right)$ and $U$ is the horizontal wind speed in $\mathrm{ms}^{-1}$. In the figure, individual symbols are used to indicate co-spectra of particle mass concentrations in the various size ranges, whereas the continuous red lines refer to co-spectra of the sonic temperature. Data were obtained by processing individual 30-min datasets according to the following procedure: $i$. Hanning filtering; $i i$. Fast Fourier Transform; iii. raw co-spectra calculation; iii. raw cospectra block averaging over exponentially-spaced frequency 

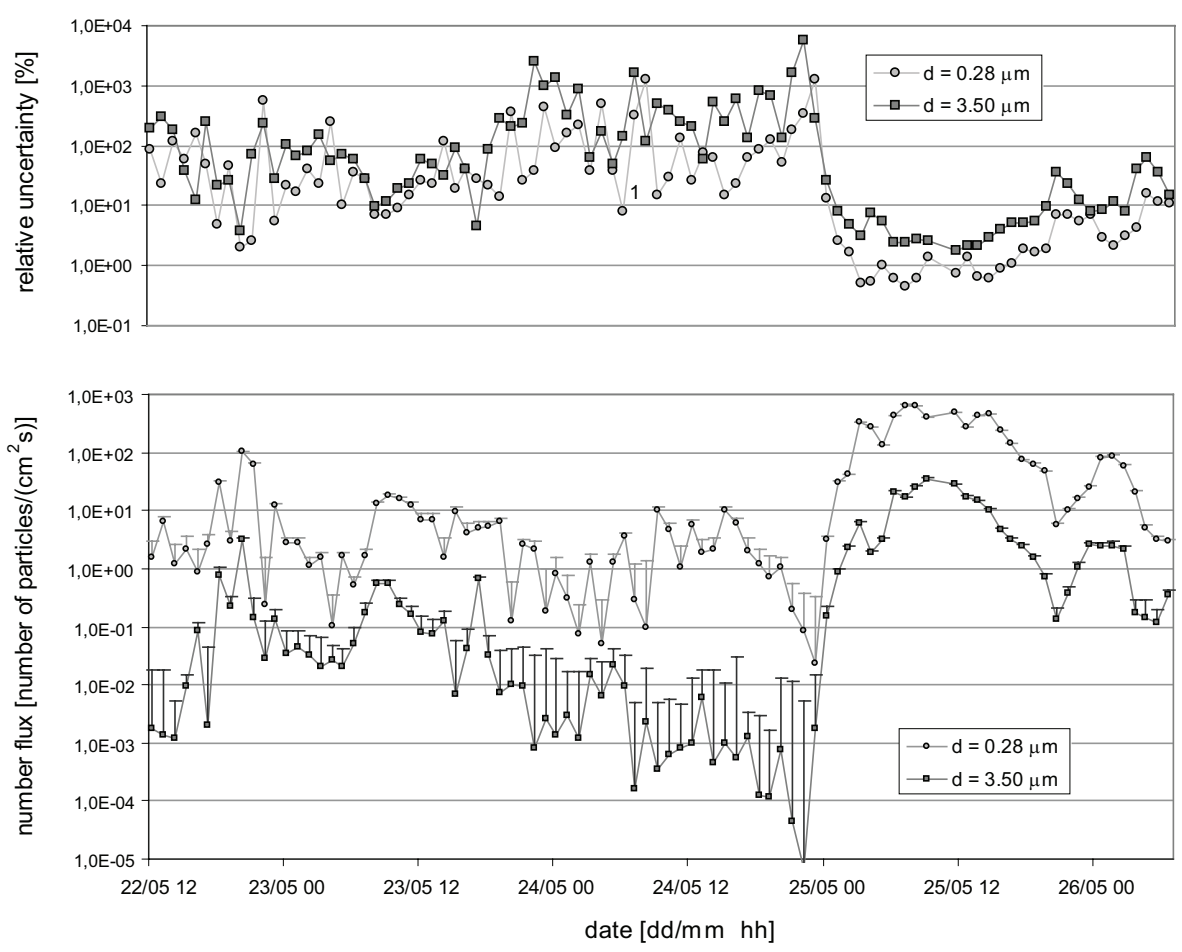

Fig. 7a. (bottom) Time series of particle number fluxes for particles with optical diameters of $0.28 \mu \mathrm{m}$ (light grey circles) and $3.50 \mu \mathrm{m}$ (dark gray squares). (top) Relative uncertainties for the same measurements, plotted with same symbols.

ranges; $i v$. as single datasets, each raw co-spectrum presents high levels of irregularity; thus, further local filtering (blockweighted average) was applied to highlight the main slopes; $v$. normalization by the relevant covariance.

Plots in Fig. 6a refer to data recorded during the storm event of 25 May 2005, when the maximum particle mass concentrations were reached over the site and the average values of the wind speed and of the friction velocity were 13.9 and $0.6 \mathrm{~ms}^{-1}$, respectively. Plots in Fig. $6 \mathrm{~b}$ refer to data collected on 28 May 2005 at the GB2 site, when particle mass concentrations were low and averaged values of the wind speed and of the friction velocity were 10.1 and $0.4 \mathrm{~ms}^{-1}$, respectively.

Figures clearly show that under highly turbulent conditions (GB1 site), normalized co-spectra of both finer and coarser particles closely matched those of sonic temperature in the inertial subrange, that approximately extends beyond values of $f_{n}=1$. This suggested that in these conditions, $t c$ effects were actually negligible and fluxes adequately described by the same equations used for gases. The same good consistency was not found at the GB2 site in which low turbulent conditions occurred during the monitoring campaign. Deviations from a perfect scalar occurred in both the finer and coarser particle ranges. This does not necessarily mean that $t c$ effects affected our determinations, because other effects could have contributed to reduce the correlation between co-spectra of particles and those of the sonic temperature. The most important was associated with the fact that the instrument was specifically designed to measure particles during storm events, when high concentrations are reached. Under low turbulent conditions, particle number concentrations dropped down to values in which the dilution step drastically reduced the number of particles reaching the sensor and counts recorded were not always statistically representative of the actual concentrations. This explanation is supported by the data displayed in Fig. 7, in which the relative and absolute uncertainties in particle number flux determinations performed on the size ranges of $0.28 \mu \mathrm{m}$ and $3.50 \mu \mathrm{m}$ optical diameter at the GB1 site are reported. They were estimated using the equation proposed by Buzorius et al. (2003), stating that:

$$
\left.\delta(\overline{w c})\right|_{\text {conc }}=\frac{\sigma_{w} \bar{c}}{N_{0}}
$$

where $\sigma_{w}$ is the standard deviation of the vertical wind speed, $\bar{c}$ is the average concentration and $N_{0}$ is the total number of particles counted in the averaging period. Data in the figure show that the relative uncertainty associated with particle counting was indeed rather small (1-10\%) during the storm event, but increased dramatically (from 100 to $1000 \%$ ) in the period when small fluxes were recorded. Figure $7 \mathrm{~b}$ clearly shows that the relative uncertainty in particle counting increased rapidly with the decay of particle number fluxes. This behaviour can be explained by the fact that, in our case, high fluxes are associated with high concentrations. This occurs because, in desert areas, wind erosion is the dominating 


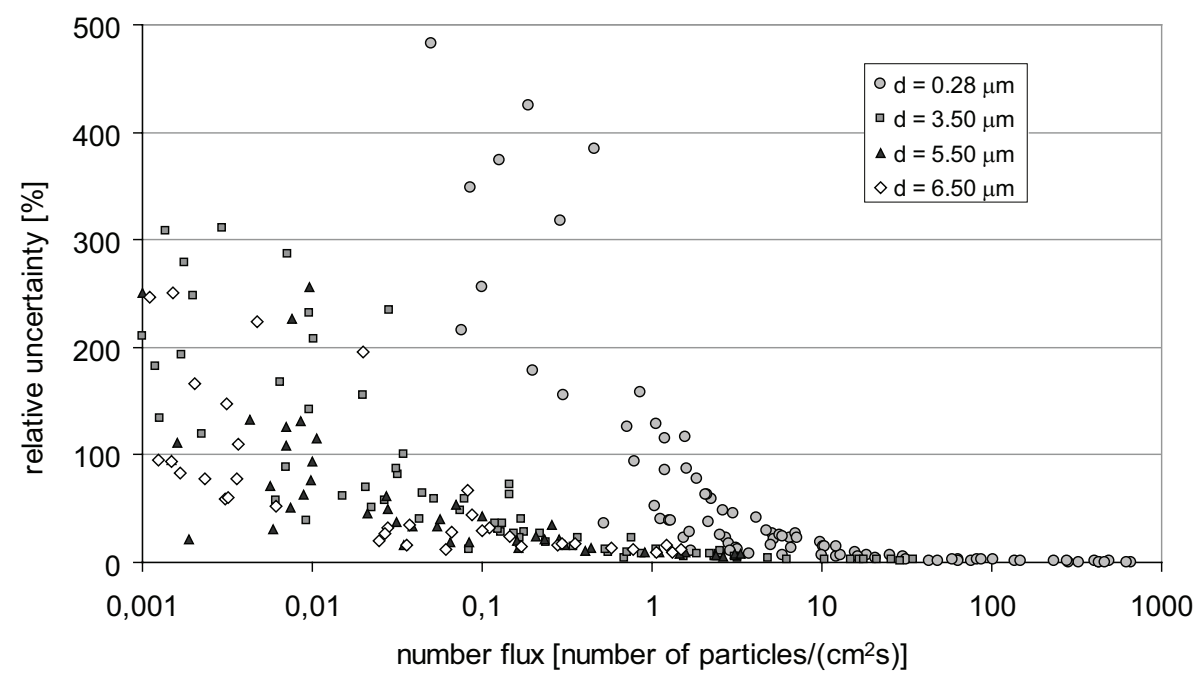

Fig. 7b. Relative uncertainties vs. particle number fluxes for particles with several optical diameters.

source responsible for dust entrainment. Under these conditions the only way to get accurate determinations of particle number fluxes under low turbulent conditions is to avoid the dilution step and send the whole sample to the OPC. However, the adoption of this procedure cannot be generalized because a strong correlation does not always exist between aerometric concentrations and fluxes. In other environments, such as in many urban and suburban areas, small emission or deposition fluxes can be associated with high aerometric concentrations. In this case, the dilution step must be maintained for an accurate determination of particle fluxes. By considering the large uncertainties in particle counting occurring under low turbulent conditions, the discussion on the size-segregated fluxes of mineral dust particles will be focused on the results obtained during the storm event. Data collected under low turbulent conditions will be only used to provide a general idea of variations occurring over the site.

\subsection{Cumulated and size-segregated fluxes of mineral dust during storm events}

By keeping in mind the considerations above, fluxes measured by EC were first used to check if the gravitational settling was actually negligible with respect to turbulent fluxes. This was obtained by comparing the gravitational settling of particles falling in the coarser mode $\left(N_{0.54-7.00}\right)$ calculated by using Eq. (9) with net fluxes measured by EC. The comparison was performed on data collected at the GB1 site. They are displayed in Fig. 8, where individual symbols represent hourly data points. It is evident that gravitational fluxes were generally 1 to 2 orders of magnitude lower than net turbulent fluxes and, in most of the instances, their contribution could have been neglected. Only sporadically, gravitational fluxes exceeded the turbulent ones. This happened when both turbulence and particle number concentrations were small. In these cases, however, turbulent fluxes were also affected by a large uncertainty.

Another important aspect to verify was the extent to which stationarity conditions occurred during storm events, because this can affect the quality of flux data. The impact of the occurrence of non-stationarity conditions was evaluated by using the quality test described in Foken and Wichura (1996). The test compares the statistics of an entire averaging period with the averages of those performed on a number of subperiods of the same data set. In our case, it was carried out by splitting $30 \mathrm{~min}$ data into 6 sub-periods of 5 minutes each. The test provides a series of flag values ranging between 1 and 9. A lower value corresponds with a smaller relative difference between global and partial statistics. Following Foken et al. (2004), data with flags ranging between 1 and 5 can be considered representative of the actual fluxes, while data with higher flags should be rejected. The quality test was applied to $\overline{u^{\prime} w^{\prime}}$ and to $\overline{c^{\prime} w^{\prime}}$, in which the $c$ term refers to the total number concentration of particles. It was found that only in $10 \%$ of the ca. 100 datasets accumulated during the intense emission event of 25 May, flags exceeded the threshold value of 5. The observation that these flags were randomly distributed and never occurred sequentially suggested that the overall trends are not dramatically affected by non stationarity conditions.

After assessing the reliability of data, the sequence of events observed at the GB1 site was exploited to get information on the way emission occurs in desert areas of northern China and to analyze what happens during storm events. Data reported in Fig. 9 show that total number fluxes $\left(N_{0.26-7.00}\right.$ flux $)$ do not follow the same trend as the friction velocity. Although several periods were recorded in which high wind speeds and friction velocities were reached, following a daily pattern, only in the last days of measurement huge fluxes were measured. During this episode values as 


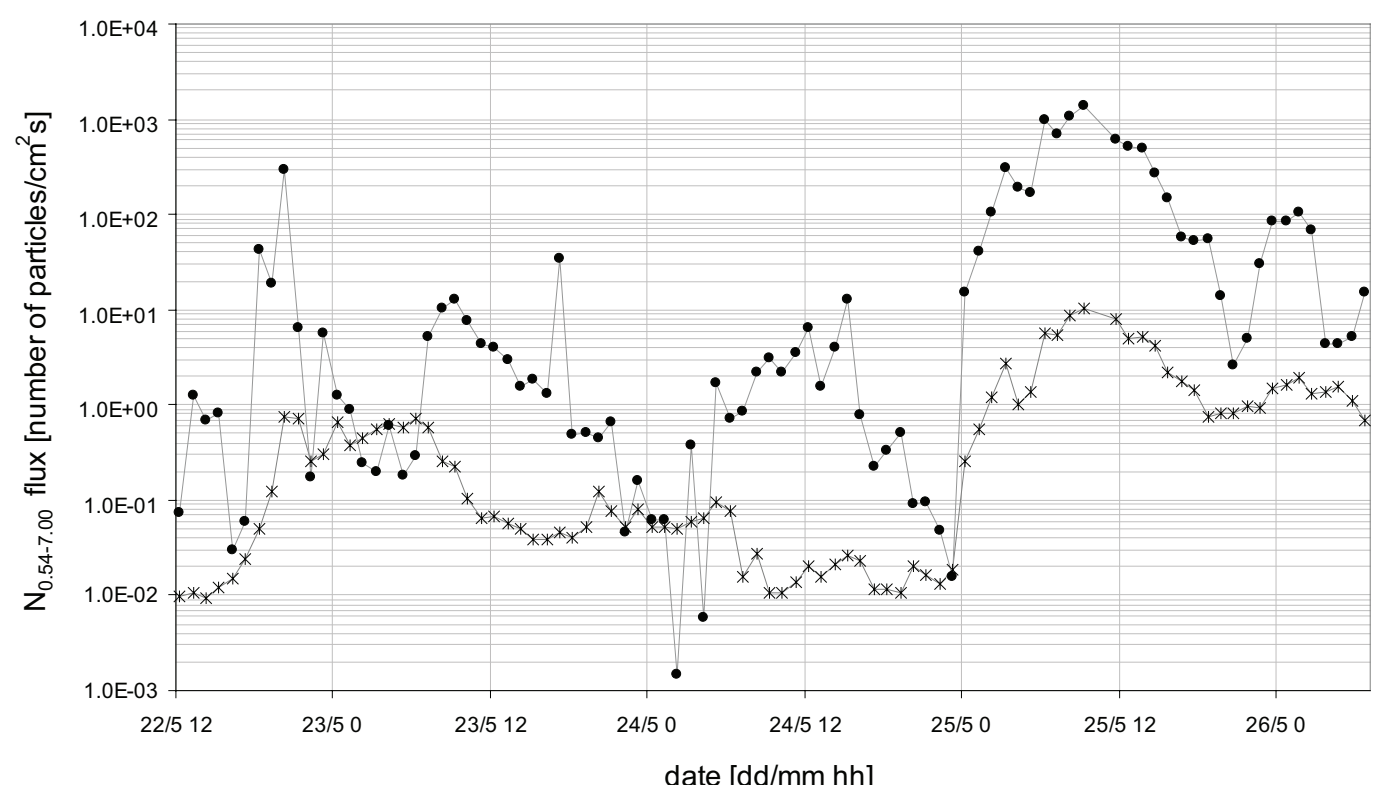

Fig. 8. Time series of $N_{0.54-7.0}$ turbulent number fluxes (black circles) vs. $N_{0.54-7.0}$ gravitational number fluxes (gray stars) during the monitoring period (22-26 May 2005) at the GB1 site. Fluxes are represented as absolute values, on a logarithmic scale.

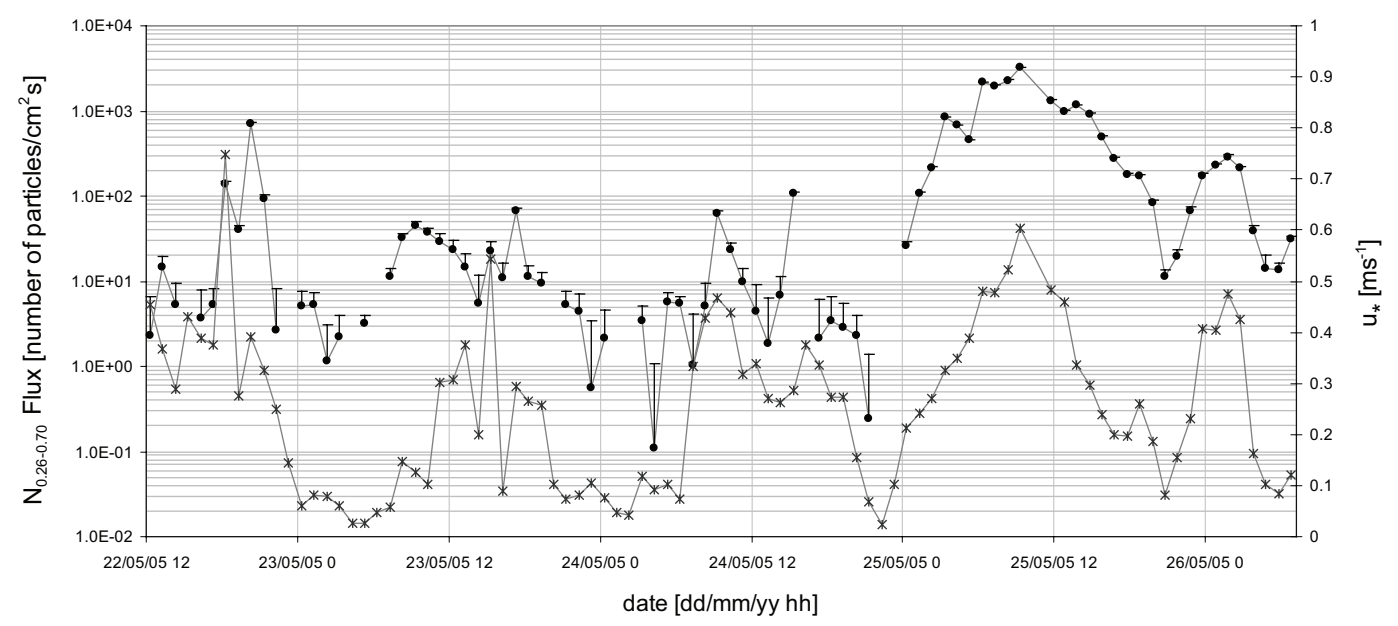

Fig. 9. Time series of particle $\left(N_{0.26-7.0}\right)$ number fluxes (black circles) and friction velocity (gray stars) during the monitoring period (22-26 May 2005) at the GB1 site. Fluxes are represented on a logarithmic scale; missing values relate to negative (net deposition) fluxes, that are not of interest in this paper.

high as $3.2 \times 10^{3}$ particles $\mathrm{cm}^{-2} \mathrm{~s}^{-1}$ were recorded over the site. They were 1 to 2 orders of magnitudes higher than those measured in previous days under similar conditions in terms of wind speed and friction velocity. This is consistent with the fact that other parameters, such as wind direction, air humidity, particle density and the texture, cover, moisture content and roughness of soil, play an important role in the development of desert storm events.

Focusing on the storm event, we can see that particle fluxes behaved differently from concentrations; indeed, no substantial changes in size-segregated flux profiles were recorded.
Data reported in Fig. 10a1 indicate that the profile of particle number fluxes are always dominated by particles falling in the finer range $\left(N_{0.26-0.30}\right)$ with two maxima peaking in the $N_{0.70-1.00}$ and $N_{1.50-3.00}$ modes. Above $3.00 \mu \mathrm{m}$ optical diameter, a rapid decay occurs in the particle number fluxes. In terms of particle mass, emission fluxes are, instead, definitely dominated by particles falling in the $M_{1.50-3.00}$ mode, with a secondary contribution from particles in the $M_{0.70-1.00}$ range (see Fig. 10a2). Overall, larger particles account for ca. $74 \%$ of the entire mass, whereas finer particles contribute only to ca. $7 \%$. In terms of aerodynamic 

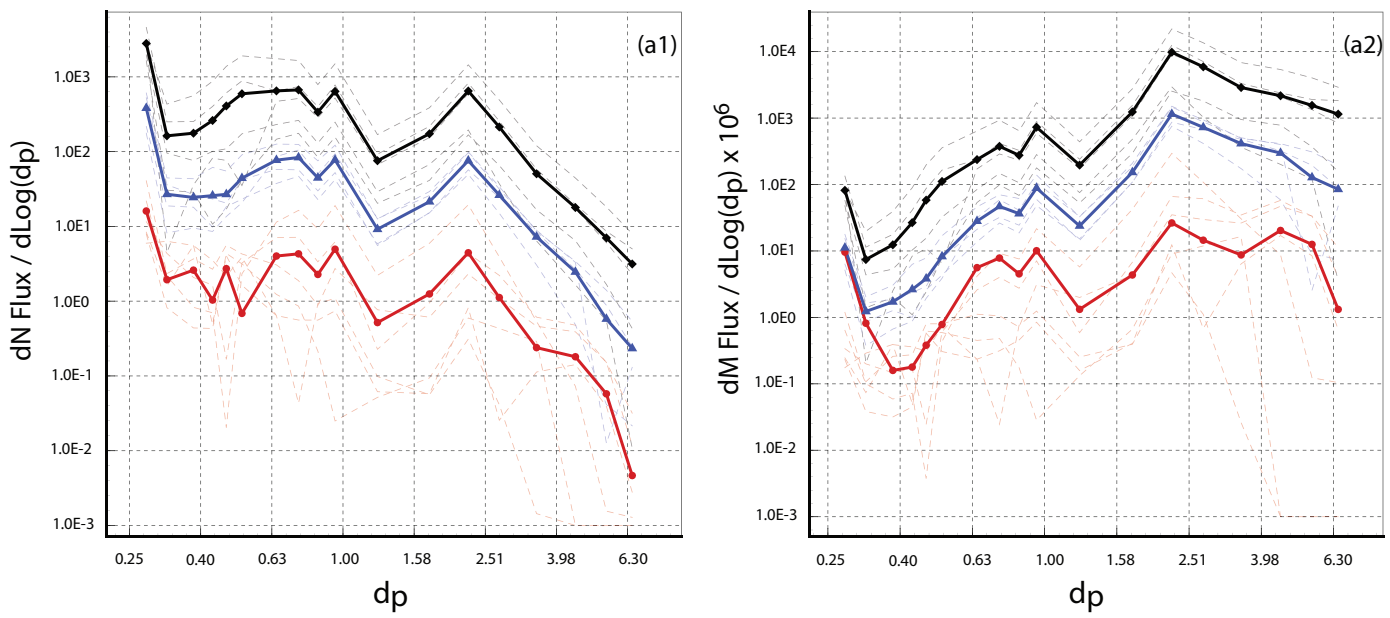

Fig. 10a. Particle number (a1) and particle mass (a2) fluxes vs. particle diameters during the monitoring period at the GB1 site. Units are [number of particles $/ \mathrm{cm} 2 \mathrm{~s}]$ and $\left[\mu \mathrm{g} / \mathrm{cm}^{2} \mathrm{~s}\right]$ for the number and mass fluxes, respectively. Red, blue and black thick lines with symbols are the average profiles of the "low", "medium" and "high" friction velocity classes, respectively. The high friction velocity class refers to the most intense moment of the dust event. Light, dashed lines are examples of profiles in the three classes.

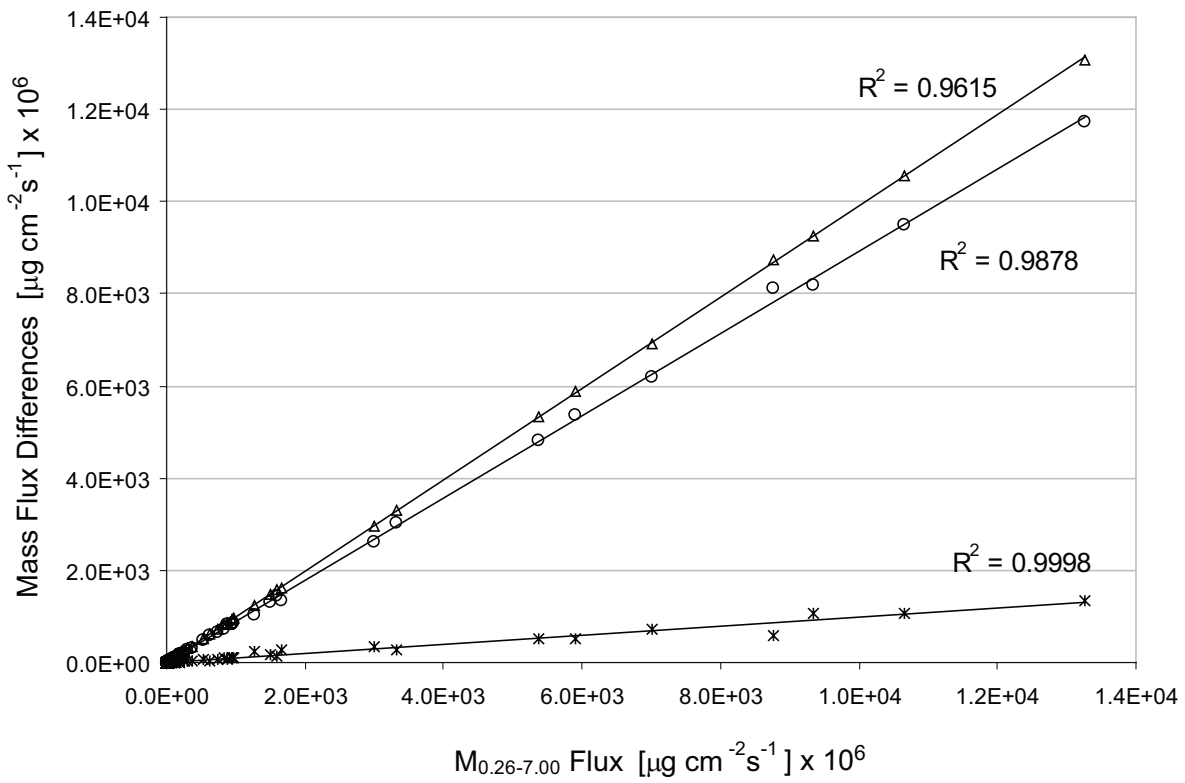

Fig. 10b. Differences in mass vertical fluxes among $M_{0.26-7.00}, M_{0.26-1.85}$, and $M_{0.26-0.74} ; M_{0.26-7.00}-M_{0.26-0.74}$ (triangles), $M_{0.26-7.00}-M_{0.26-1.85}$ (circles), $M_{0.26-1.85}-M_{0.26-0.74}$ (stars) vs. $M_{0.26-7.00}$ net vertical flux, during the strong dust event at GB1 site; solid lines, linear regressions.

diameters, this means that net vertical fluxes generated during storm events are essentially given by particles falling in the $\mathrm{PM}_{2.5}-\mathrm{PM}_{10}$ range. This represents a substantial variation with respect to low turbulent conditions, in which fluxes of coarser particle account for ca. $40 \%$ of the total mass and the finer ones for ca. 22\%. The relative importance of the $M_{0.26-7.00}, M_{0.26-1.85}, M_{0.26-0.74}$ modes, roughly corresponding to $\mathrm{PM}_{1}, \mathrm{PM}_{2.5}$ and $\mathrm{PM}_{10}$ in aerodynamic diameter, in determining the total particle mass and their substantial constancy during storm events characterized by high particle emission is well illustrated in Fig. 10b. The good correlation coefficients given by the linear regressions suggest that it is possible to estimate, with good accuracy, size segregated fluxes of mineral dust particles from their total fluxes.

Data collected are also useful to better understand the role played by the friction velocity in determining particle emission during acute episodes in which wind erosion and sandblasting are, by far, the dominant processes of dust 


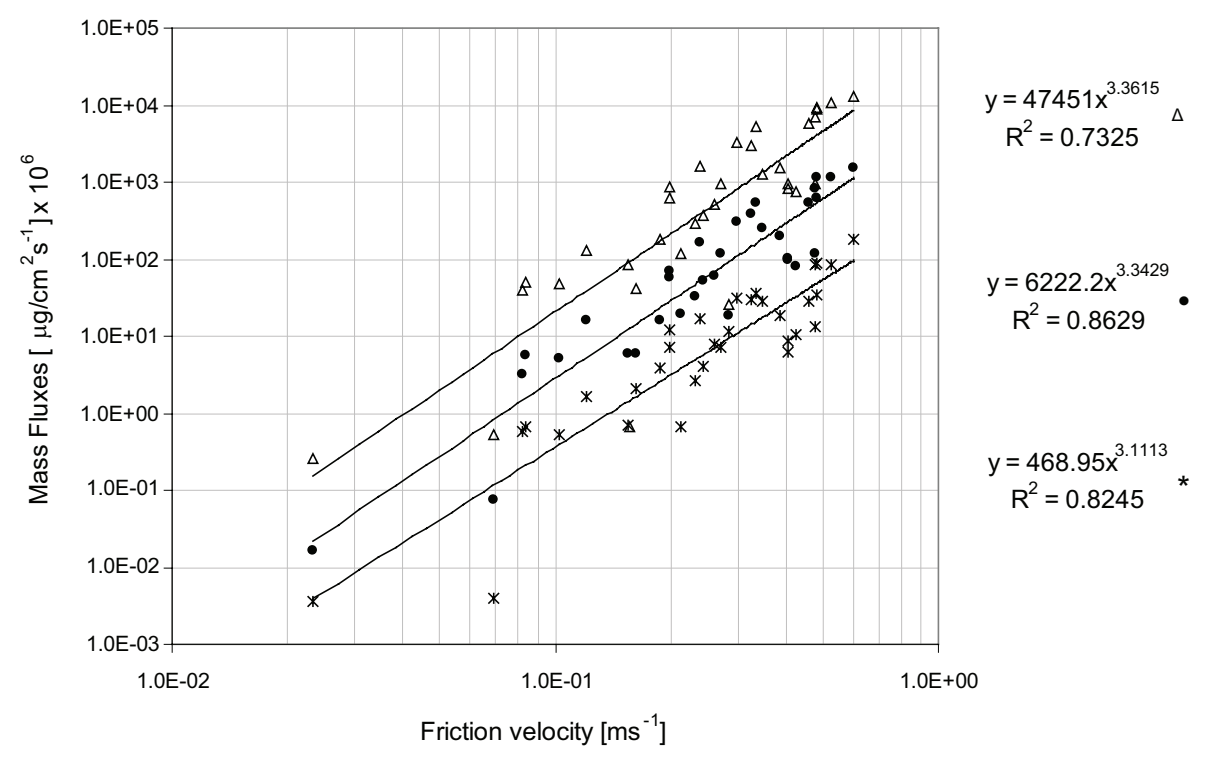

Fig. 11. Net vertical mass fluxes of $M_{0.26-7.00}$ (triangles), $M_{0.26-1.85}$ (full circles), $M_{0.26-0.74}$ (stars) vs. friction velocity during the strong dust event at GB1 site; the three ranges roughly correspond to $\mathrm{PM}_{10}, \mathrm{PM}_{2.5}$ and $\mathrm{PM}_{1}$ in aerodynamic diameter; solid lines, power regressions.

emission. Although several factors are known to affect particle generation in the wind erosion process, their assessment is rather difficult and, sometimes, controversial (Shao, 2000). This explains why many models still use relations between the friction velocity and particle fluxes to parameterize the emission process. Particle fluxes are usually related to friction velocity through a power function, whose exponent was found to vary, from 6.54 to 1.89 (Nickling and Gillies, 1989; White et al., 1996). Such large variations, that have been attributed to inter-particle bonds strength and/or crusting effects (Houser and Nickling, 2001), can introduce large errors in the models. Data collected during the storm event were particularly suitable to investigate this aspect because determinations were made when deposition fluxes were small when compared to emission and the emission process was essentially driven by wind erosion. Under these conditions, other effects, such as those arising from changes in the moisture content of soil, could have been neglected and the relation between particle emission and turbulence better assessed. When particle mass fluxes in three size ranges (namely $M_{0.26-7.00}, M_{0.26-1.85}, M_{0.26-0.74}$ ) were plotted against the friction velocity, curves shown in Fig. 11 were obtained. Power regression gave exponents ranging between $3.10 \div 3.36$ with a $r^{2}$ of 0.732 . It is much higher than those found in previous literature (Houser and Nickling, 2001) in which $r^{2}$ values of 0.38 were reported. Since in the EC approach the friction velocity is derived independently from vertical dust fluxes, the good correlation displayed in Fig. 11 is suggestive of a genuine physical dependence, and it does not seem to be just a spurious result of the calculations, as suggested, for example, in Houser and Nickling (2001).

\section{Conclusions}

For the first time, EC has been used to measure size segregated fluxes of mineral dust particles during storm events occurring in desert areas of northern China. Although limited by the number of events recorded, results obtained provided useful information to parameterize the emission process either in global transport models or in models devoted to predict wind erosion and sandblasting. The co-spectral and uncertainty analysis showed that the instrument developed was able to provide quite reliable data when high particle concentrations were reached and under strong turbulence conditions. Its accuracy was definitely much lower when low concentrations and limited turbulence occurred over the site. However, this limitation can be partly circumvented if the dilution step is avoided and the whole sample sent to the sensor. We believe that an increase of a factor of 20 in the particle number is more than enough to get statistically accurate values of particle concentrations under normal conditions, as it has been shown also by previous authors (Dorsey et al., 2002; Martensson et al., 2006; Nemitz et al., 2000). Other limits are associated with the particle sizing capabilities of the OPC and with the impossibility to evaluate errors arising from sub-kinetic sampling occurring in the coarser mode under very high turbulent conditions. These aspects are presently under investigation. 
Acknowledgements. We thank the Italian Ministry of the Environment (IMET) for the financial support given through the WinDust project and the Beijing Municipality Environmental Protection Bureau (BJEPB) who supported investigations on dust storms. The authors wish to thank all the scientists, technicians and supporting staff of Beijing Municipality Environmental Protection Institute (BJEPB) and Beijing Municipality Environmental Protection Foundation for the help provided. In particular, N. Lei and D. Jianqi are warmly acknowledged. D. L. Westphal of US NAAPS is also acknowledged for providing information on the NAAPS global dust model. We also thank the anonymous referees, who greatly helped to clarify some aspects of the paper through their comments and suggestions.

Edited by: A. B. Guenther

\section{References}

Andreae, M. O.: Climate effects of changing atmospheric aerosol levels, in: World Survey of Climatology, Future Climate of the World, 16, edited by: Henderson Sellers, A., Elsevier Publ., Amsterdam, 341-392, 1995.

Aubinet, M.: Estimates of the annual net carbon and water exchange of forests: the EUROFLUX methodology, Adv. Ecol. Res., 30, 113-175, 2000 .

Aubinet, M.: Fluxes of Carbon, Water and Energy of European Forests, Ecol. Stud., 163, 9-36, 2003.

Aubinet, M., Chermanne, B., Vandenhaute, M., Longdoz, B., Yernaux, M., and Laitat, E.: Long term measurements of water vapour and carbon dioxide fluxes above a mixed forest in Ardenne's region, Agricult. For. Met., 108, 293-315, 2001.

Baldocchi, D., Hicks, B. B., and Meyers, T. D.: Measuring biosphere-atmosphere exchanges of biologically related gases with micrometeorological methods, Ecology, 69, 1331-1340, 1988.

Bates, T. S., Anderson, T. L., Baynard, T., Bond, T., Boucher, O., Carmichael, G., Clarke, A., Erlick, C., Guo, H., Horowitz , L., Howell, S., Kulkarni, S., Maring, H., Mccomiskey, A., Middlebrook, A., Noone, K., O'dowd, C. D., Ogren, J., Penner, J., Quinn, P. K., Ravishankara, A. R., Savoie, D. L., Schwartz, S. E., Shinozuka, Y., Tang, Y., Weber, R. J., and Wu, Y.: Aerosol direct radiative effects over the northwest Atlantic, northwest Pacific and North Indian Oceans: estimates based on in-situ chemical and optical measurements and chemical transport modeling, Atmos. Chem. Phys., 6, 1657-1732, 2006, http://www.atmos-chem-phys.net/6/1657/2006/.

Bauer, S. E., Balkanski, Y., Schulz, M., Hauglustaine, D. A., and Dentener, F.: Global modelling of heterogeneous chemistry on mineral aerosol surfaces: influence on tropospheric ozone chemistry and comparison to observations, J. Geophys. Res., 109, D02304, doi:10.1029/2003JD003868, 2004.

Bonasoni, P., Cristofanelli, P., Calzolari, F., Bonafè, U., Evangelisti, F., Stohl, A., Zauli Sajani, S., Van Dingenen, R., Colombo, T., and Balkanski, Y.: Aerosol-Ozone correlations during dust transport episodes, Atmos. Chem. Phys., 4, 1201-1215, 2004 , http://www.atmos-chem-phys.net/4/1201/2004/.

Breshears, D. D., Whicker, J. J., Johansen, M. P., and Pinder, J. E.: Wind and water erosion and transport in semi-arid shrubland, grassland and forest ecosystems: quantifying dominance of horizontal wind-driven transport, Earth Sur. Proc. Land., 28, 1189-1209, 2003.

Buzorius, G., Rannik, Ü., Nilsson, E. D., Vesala, T., and Kulmala, M.: Analysis of measurement techniques to determine dry deposition velocities of aerosol particles with diameters less than 100 nm, J. Aerosol Sci., 34, 747-764, 2003.

Chin, M., Ginoux, P., Lucchesi, R., Huebert, B., Weber, R., Anderson, T., Masonis, S., Blomquist, B., Bandy, A., and Thornton, D.: A global aerosol model forecast for the ACEAsia field experiment, J. Geophys. Res., 108(D23), 8654, doi:10.1029/2003JD003642, 2003.

Clarke, A. D., Shinozuka, Y., Kapustin, V. N., Howell, S., Huebert, B., Doherty, S., Anderson, T., Covert, D., Anderson, J., Hua, Z., Moore, K. G., Mcnaughton, C., and Carmichael, G.: SizeDistributions and Mixtures of Dust and Black Carbon Aerosol in Asian Outflow: Physio-chemistry and Optical Properties, ACEAsia project report, 2004.

Csanady, G. T.: Turbulent Diffusion of Heavy Particles in the Atmosphere, J. Atmos. Sci., 20, 201-208, 1963.

Cziczo, D. J., Murphy, D. M., Hudson, P. K., and Thomson, D. S.: Single particle measurements of the chemical composition of cirrus Ice residue during crystal-face, J. Geophys. Res., 109, D04201, doi:10.1029/2003JD004032, 2004.

De Reus, M., Fischer, H., Sander, R., Gros, V., Kormann, R., Salisbury, G., Van Dingenen, R., Williams, J., Zollner, M., and Lelieveld, J.: Observations and model calculations of trace gas scavenging in a dense Saharan dust plume during MINATROC, Atmos. Chem. Phys., 5, 1787-1803, 2005, http://www.atmos-chem-phys.net/5/1787/2005/.

Dentener, F. J., Carmichael, G. R., Zhang, Y., Lelieveld, J., and Crutzen, P. J.: Role of Mineral Aerosol as a Reactive Surface in the Global Troposphere, J. Geophys. Res., 101, 22 869-22 889. 1996.

Dong, Z., Liu, X., Wang, H., and Wang, X.: Aeolian sand transport: a wind tunnel model, Sedim. Geol., 161, 71-83, 2003.

Dong, Z., Wang, H., Liu, X., and Wang, X.: The blown sand flux over a sandy surface: a wind tunnel investigation on the fetch effect, Geomorphology, 57, 117-127, 2004.

Dorsey, J. R., Nemitz, E., Gallagher, M. W., Fowler, D., Williams, P. I., Bower, K. N., and Beswick, K. M.: Direct measurements and parameterisation of aerosol flux, concentration and emission velocity above a city, Atmos. Environ., 36, 791-800, 2002.

Foken, T., Gockede, M., Mauder, M., Mahrt, L., Amiro, B., and Munger, W.: Post-field data quality control, in: Handbook of Micrometeorology, edited by: Lee, X., Massmann, W., and Law, B., Kluwer Academic Publishers Publ., Dordrecht, The Netherlands, 181-208, 2004.

Foken, T. and Wichura, B.: Tools for quality assessment of surfacebased flux measurements, Agricult. For. Meterol., 78, 83-105, 1996.

Gash, J. H. and Culf, A. D.: Applying linear de-trend to eddy correlation data in real time, Bound.-Lay. Meteorol., 79, 301-306, 1996.

Goulden, M. L., Munger, J. W., Fan, S. M., Daube, B. C., and Wofsy, S. C.: Measurements of carbon sequestration by longterm eddy covariance: methods a critical evaluation of accuracy, Glob. Change Biol., 2, 159-168, 1996.

Gusten, H., Heinrich, G., Monnich, E., Sprung, D., Weppner, J., Ramadan, A. B., El, E., Din, M. R. M., Ahmed, D. M., and Hassan, 
G. K. Y.: On-line measurements of ozone surface fluxes: Part II; Surface-level ozone fluxes onto the Sahara desert, Atmos. Environ., 30, 911-918, 1996.

Heintzenberger, J., Raes, F., Schwatrz, S. E., and Coauthors: Tropospheric Aerosols, in: Atmospheric Chemistry in a Changing World: An Integration and synthesis of a decade of tropospheric research, edited by: Brasseur, G. P., Prinn, R. G., and Pszenny, A. A. P., Springer-Verlag Publ., Heidelberg, 125-156, 2003.

Houser, C. A. and Nickling, W. G.: The emission and vertical flux of particulate matter $<10 \mu \mathrm{m}$ from a disturbed clay-crusted surface, Sedimentology, 48, 255-267, 2001.

Hunt, J. C. R. and Weber, A. H.: A Lagrangian Statistical Analysis of Diffusion from a Ground Level Source in a Turbulent Boundary Layer, Q. J. Roy. Meteor. Soc., 105, 423-443, 1979.

Husar, R. B., Tratt, D. M., Schichtel, B. A., Falke, S. R., Li, F., Jaffe, D., Gasso, S., Gill, T., Laulainen, N. S., Lu, F., Reheis, M. C., Chun, Y., Westphal, D., Holben, B. N., Gueymard, C., Mckendry, I., Kuring, N., Feldman, G. C., Mcclain, C., Frouin, R. J., Merrill, J., Dubois, D., Vignola, F., Murayama, T., Nickovic, S., Wilson, W. E., Sassen, K., Sugimoto, N., and Malm, W. C.: Asian Dust Events of April 1998-2001, J. Geophys. Res., 106, 18 317-18330, 2001.

Iso/Ts: 17892-3: 2004 - Geotechnical investigation and testing, Laboratory testing of soil, Part 3: Determination of particle density - Pycnometer method, International Organization for Standardization, 7 pages, 2004.

Kolmogorov, A. N.: Local structure of turbulence in an incompressible fluid at large Reynolds numbers, Dokl. Akad. Nauk. SSSR, 1941.

Li, F., Zhao, L., Zhang, H., Zhang, T., and Shirato, Y.: Wind erosion and airborne dust deposition in farmland during spring in the Horqin Sandy Land of eastern Inner Mongolia, China, Soil Till. Res., 75, 121-130, 2004.

Martensson, E. M., Nilsson, E. D., Buzorius, G., and Johansson, C.: Eddy covariance measurements and parameterisation of traffic related particle emissions in an urban environment, Atmos. Chem. Phys., 6, 769-785, 2006,

http://www.atmos-chem-phys.net/6/769/2006/.

Mcmeeking, G.: Size Distribution Measurements Of Wildfire Smoke-Influenced Aerosol At Yosemite National Park, MS Thesis, Colorado State University, 2004.

Nemitz, E., Fowler, D., Dorsey, J. R., Theobald, M. R., Mcdonald, A. D., Bower, K. N., Beswick, K. M., Williams, P. I., and Gallagher, M. W.: Direct measurements of size-segregated particle fluxes above a city, J. Aerosol Sci., 31, 116-117, 2000.

Nickling, W. G. and Gillies, J. A.: Emission of fine-grained particulates from desert soils, in: Paleoclimatology and Paleometeorology: Modern and Past Patterns of Global Atmospheric Transport, edited by: Leinen, M. and Sarnthein, M., 133-166, 1989.

Ono, D., Weaver, S., and Richmond, K.: Quantifying Particulate Matter Emissions from Wind Blown Dust Using Real-time Sand Flux Measurements, Owens Emissions papers, paper-C, EPA, 2003.
Penner, J. E., Andreae, M., Annegarn, H., Barrie, L., Feichter, J., Hegg, D., Jayaraman, A., Leaitch, R., Murphy, D., Nganga, J., and Pitari, G.: Aerosols, their Direct and Indirect Effects, in: Climate Change 2001: the Scientific basis, Contribution of WorkingGroup 1 to the Third Assessment Report of Intergovernmental Panel on Climate Change, edited by: Houghton, J. T., Ding, Y., Griggs, D. J., Noguer, M., van der Linden, P. J., Dai, X., Maskell, K., and Johnson, C. A., Cambridge Univ. Press Publ., Cambridge, UK and New York, NY USA, 881, 2001.

Qian, W., Quan, L., and Shi, S.: Variations of the dust storm in China and its climatic control, J. Climate, 15, 1216-1229, 2002.

Rosenfeld, D., Rudich, Y., and Lahav, R.: Desert dust suppressing precipitation: possible desertification feedback loop, Proc. Natl. Acad. Sci. USA, 98, 5975-5980, 2001.

Seisel, S., Borensen, C., Vogt, R., and Zellner, R.: Kinetics and mechanism of the uptake of N2O5 on mineral dust at 298K, Atmos. Chem. Phys., 5, 3423-3432, 2005, http://www.atmos-chem-phys.net/5/3423/2005/.

Shao, Y.: Physics and Modelling of Wind Erosion, Kluwer Academic Publ., 2000.

Sozzi, R., Georgiadis, T., and Valentini, M.: Introduzione alla turbolenza atmosferica, Pitagora eds., Bologna, 2002.

Stull, R. B.: An Introduction to Boundary Layer Meteorology, Kluwer Academic Publ., Dordrecht, 1988.

Tegen, I. and Lacis, A. A.: Modeling of Particle Size Distribution and Its Influence on the RadiativeProperties of Mineral Dust Aerosol, J. Geophys. Res., 101, 19237-19244, 1996.

Valentini, R., De Angelis, P., Matteucci, G., Monaco, G., Dore, S., and Scarascia Mugnozza, G. E.: Seasonal net carbon dioxide exchange of a beech forest with the atmosphere, Glob. Change Biol., 2, 199-207, 1996.

Wang, X., Dong, Z., Zhang, J., and Liu, L.: Modern dust storms in China: an overview, J. Arid Environ., 58, 559-574, 2004.

Westphal, D. L., Toon, O. B., and Carlson, T. N.: A case study of mobilization and transport of Saharan dust, J. Atmos. Sci., 45, 2145-2175, 1988.

White, B. R., Cho, G. H., and Kim, D. S.: A Wind Tunnel Study to Determine Vegetation Cover Required to Suppress Sand Dust Transport at Owens (dry) Lake, California, Great Basin Unified Air Quality Control District, Interagency Agreement no. 9464, 1996.

Wilczak, J. M., Oncley, S. P., and Stage, S. A.: Sonic anemometer tilt correction algorithms, Bound.-Lay. Meteorol., 99, 127-150, 2001.

Xuan, J., Sokolik, I. N., Hao, J., Guo, F., Mao, H., and Yang, G.: Identification and characterization of sources of atmospheric mineral dust in East Asia, Atmos. Environ., 38, 6239-6252, 2004.

Yudine, M. I.: Physical considerations on heavy-particle diffusion, Adv. Geophys., 6, 185-191, 1959.

Zhang, Y. and Carmichael, G. R.: The Role of Mineral Aerosol in Tropospheric Chemistry inEast Asia - a Model Study, J. Appl. Meteorol., 38, 353-366, 1999. 